Research Article

\title{
Morphological Characteristics and Clinical Significance of Different Types of Tumor Vessels in Patients with Stages I-IIA of Squamous Cervical Cancer
}

\author{
Marina A. Senchukova $\mathbb{D}^{1}{ }^{1}$ Elena V. Makarova, ${ }^{1}$ Elena I. Shurygina, ${ }^{2}$ \\ and Nadezhda N. Volchenko ${ }^{3}$ \\ ${ }^{1}$ Department of Oncology, Orenburg State Medical University, 460000 Orenburg, Russia \\ ${ }^{2}$ Department of Pathology, Orenburg State Medical University, 460000 Orenburg, Russia \\ ${ }^{3}$ Department of Pathology, P. A. Hertzen Moscow Oncology Research Center, National Medical Research Center of Radiology, \\ 125284 Moscow, Russia
}

Correspondence should be addressed to Marina A. Senchukova; masenchukova@yandex.com

Received 28 April 2020; Revised 2 July 2020; Accepted 11 July 2020; Published 12 August 2020

Academic Editor: Pierfrancesco Franco

Copyright ( 12020 Marina A. Senchukova et al. This is an open access article distributed under the Creative Commons Attribution License, which permits unrestricted use, distribution, and reproduction in any medium, provided the original work is properly cited.

\begin{abstract}
The determination of factors associated with progression of cervical cancer is important, both for a recurrence risk assessment and for determining optimal treatment tactics. Previously, we showed the prognostic value of different types of tumor microvessels (MVs) in gastric and breast cancer. The object of this research was to study the morphology and clinical significance of different tumor microvessels in early cervical cancer. A total of 65 archived paraffin blocks of patients with I-IIA stages of squamous cervical cancer were investigated. Samples were stained with Mayer hematoxylin and immunohistochemically using antibodies to CD34, podoplanin, HIF-1a, and Snail. The eight types of tumor MVs differed in morphology were identified. It was established that only the dilated capillaries (DCs) with weak expression of CD34, the contact type DCs, the capillaries in tumor solid component, and the lymphatic vessels in the lymphoid and polymorphic cell infiltrates of tumor stroma are associated with clinical and pathological characteristics of early cervical cancer. Preliminary results also suggest that a combination of fragmentation in tumor solid component and the contact type DCs may predict a recurrence of early cervical cancer. Given the small number of cervical cancer recurrences, the predictive significance of the described markers requires a more thorough examination.
\end{abstract}

\section{Introduction}

Cervical cancer is an urgent worldwide public health problem [1]. In 2018, about 570,000 cases of cervical cancer were identified, and 311,000 patients died from the disease. It ranks as the fourth most frequently diagnosed cancer and the fourth leading cause of cancer death in women $[2,3]$.

It should be noted that the diagnosis of cervical cancer in early stages is crucial for successful treatment. However, cervical cancer is characterized by an aggressive course and the detection of this pathology at an early stage does not always guarantee a favorable result. In this regard, the determination of factors associated with the progression of cervical cancer is important, both for an accurate assessment of the relapse risk of the disease and for determining the optimal tactics for treatment. Currently, the assessment of the relapse risk in early cervical cancer is based mainly on the clinical characteristics of the disease, such as age, AfricanAmerican ethnicity, human papillomavirus 18 infection, histology, grade, deep cervical stromal invasion, tumor size over $2 \mathrm{~cm}$, lymphovascular space invasion, nodal metastases, microscopic tumor in uterine parametrial tissues, positive surgical margins, and type of surgery [4-7]. The importance of such assessments is related to the requirement to select the patients in whom organ-preserving operations (trachelectomy) may be safe [4-6], as well as for the selection of 
patients requiring adjuvant therapy [8]. Given the risk of serious side effects from radiation therapy and chemotherapy, such studies are undoubtedly of interest [9-13].

Angiogenesis is one of the critical processes required for tumor growth, invasion, and metastasis [14-16]. It has been found that the activation of angiogenesis mechanisms is associated with the hypoxic microenvironment of tumor cells and, in particular, with an increase in the level of hypoxia-inducible factor-1 (HIF-1). It is known that HIF-1 is one of the key transcription factors responsible for the regulation of gene expression during hypoxia and ischemia $[17,18]$. An increase in the expression level of HIF- $1 \alpha$ leads to the metabolic reprogramming of tumor cells, enabling them to avoid hypoxic conditions, via invasion and metastasis, and also to improve oxygen availability, via angiogenesis and neovascularization [18-20].

We believe that when studying the role of angiogenesis in tumor progression, it is important to consider two points, as follows:

(1) Structural and functional inferiority of tumor vessels leading to the deterioration of oxygen diffusion through their walls [21-26]

(2) Heterogeneity of tumor vessels in origin, morphology, degree of maturity, and sensitivity to drugs [27-32]

Given these two points, it is logical to assume that the qualitative and quantitative features of tumor vessels can directly affect the severity of hypoxia in tumors, the prognosis of disease, and the sensitivity of the tumor to chemotherapy and radiation therapy.

Despite the fact that the heterogeneity of tumor vessels has been confirmed by numerous studies, to date, there has been no classification of tumor vessels that takes account of both the features of their morphology and its relationship with the clinical and morphological characteristics of the pathological process and with long-term results of treatment. A number of existing classifications are based on the origin and degree of vessel maturity, as well as their relationship with the type of histopathological tumor growth patterns [26, 33, 34].

Meanwhile, we previously studied the features of different types of tumor microvessels (MVs) in gastric and breast cancer $[31,32]$. As result of the study, a new classification of tumor MVs was proposed, based on both the features of their morphology and their prognostic significance. We have described five different types of tumor MVs and structures with endothelial lining: normal MVs, dilated capillaries (DCs), atypical dilated capillaries (ADCs), structures with partial endothelial lining (cavity structures of type-1), and the distinctive cellular structures in a loose finefibered connective tissue of the peritumoral stroma (cavity structures of type-2), in which the DCs with weak expression of CD34 were present.

It was found that both in gastric cancer and in breast cancer, ADCs and structures with partial endothelial lining were the most significant in terms of disease prognosis.
However, it is worth noting that gastric cancer and breast cancer are glandular cancers and it is not clear how the proposed classification is universal for other histological types of malignant neoplasms. In accordance with this, the aim of this study was to assess the morphological features and clinical significance of different types of tumor vessels in squamous cervical cancer.

\section{Materials and Methods}

2.1. Patients and Sample Collection. This pilot study was performed in accordance with the Helsinki Declaration and internationally recognized guidelines after receiving study approval from the Ethics Committee of Orenburg State Medical University (Russia, Orenburg). Sixty-five archived paraffin blocks of patients with I-IIA stages of squamous cervical cancer were retrieved from the Orenburg Regional Clinical Cancer Center tumor bank. All patients were operated on at this Center from May 2008 to March 2014.

Clinical and pathological data including age, menstrual function, comorbidity, tumor size, histology, grade and depth of tumor invasion, lymph node status, type of surgery, and the presence of adjuvant therapy were retrieved from the routine reports. Tumor size and lymph node status were categorized according to the TNM classification of malignant tumors (the 7th edition) and FIGO (2009). The privacy of patients was protected by coding of data according to the privacy regulations of the Orenburg Regional Clinical Oncologic Center (Russia, Orenburg).

None of the patients included in the study underwent preoperative chemotherapy or radiation therapy. Moreover, they did not receive steroids, nonsteroidal anti-inflammatory drugs, or antihistamines and had no significant comorbid pathologies in decompensation stage. The baseline patient's clinicopathological and treatment information is shown in Table 1.

In accordance with domestic protocol, adjuvant radiotherapy was prescribed to 29 patients with IB-IIA stages of cervical cancer who had at least two of the three risk factors (tumor size more than $4 \mathrm{~cm}$, the presence of lymphovascular invasion, and more than one-third of stromal invasion). These patients underwent external beam radiotherapy (45 Gy) and brachytherapy (25 Gy). Three patients (one was with IB, and two patients were with IIA stages) underwent adjuvant chemotherapy due to the presence of contraindications to radiation therapy (they had postoperative inflammatory changes in the pelvis). In 5 (7.7\%) patients, in the period from 5 to 43 months after completion of treatment, the recurrence of cervical cancer was diagnosed. Of the five patients with recurrence of cervical cancer, four patients with stage IB underwent adjuvant radiation therapy and one patient with stage IA was without adjuvant treatment. Local recurrence was detected in 2 patients, systemic recurrence in 2 patients, and local and systemic relapse in 1 patient. The median follow-up was 7.5 years. 
TABLE 1: The baseline patient's clinicopathological and treatment information.

\begin{tabular}{|c|c|c|}
\hline Clinical and pathological data & $n$ & $\%$ \\
\hline \multicolumn{3}{|l|}{ Age (years) } \\
\hline$<35$ & 18 & 27.7 \\
\hline $35-44$ & 15 & 23.1 \\
\hline$\geq 45$ & 32 & 49.2 \\
\hline \multicolumn{3}{|l|}{ Menstrual function } \\
\hline Absence & 46 & 70.8 \\
\hline Presence & 19 & 29.2 \\
\hline \multicolumn{3}{|l|}{ Comorbidity } \\
\hline Absence & 8 & 12.3 \\
\hline Presence & 57 & 87.7 \\
\hline \multicolumn{3}{|l|}{ Histology } \\
\hline Squamous cell keratinous carcinoma & 22 & 33.8 \\
\hline Squamous cell nonkeratinous carcinoma & 43 & 66.2 \\
\hline \multicolumn{3}{|l|}{ Grade } \\
\hline G1 & 49 & 75.4 \\
\hline G2 & 9 & 13.8 \\
\hline G3 & 7 & 10.8 \\
\hline \multicolumn{3}{|l|}{ Depth of tumor invasion } \\
\hline$<10 \mathrm{~mm}$ & 44 & 67.7 \\
\hline$\geq 10 \mathrm{~mm}$ & 21 & 32.3 \\
\hline \multicolumn{3}{|l|}{$T$} \\
\hline $\mathrm{T} 1$ & 61 & 93.8 \\
\hline $\mathrm{T} 2$ & 4 & 6.2 \\
\hline \multicolumn{3}{|l|}{ Stages } \\
\hline $\mathrm{IA}^{\circ}$ & 28 & 43.1 \\
\hline IB & 32 & 49.2 \\
\hline IIA & 5 & 7.7 \\
\hline \multicolumn{3}{|l|}{ Type of surgery } \\
\hline Radical hysterectomy with appendages & 27 & 41.5 \\
\hline Radical hysterectomy without appendages & 13 & 20.0 \\
\hline Simple hysterectomy & 21 & 32.3 \\
\hline Radical trachelectomy & 4 & 6.2 \\
\hline \multicolumn{3}{|l|}{ Adjuvant radiation therapy } \\
\hline Presence & 29 & 44.6 \\
\hline Absence & 36 & 55.4 \\
\hline \multicolumn{3}{|l|}{ Adjuvant chemotherapy } \\
\hline Presence & 3 & 4.6 \\
\hline Absence & 62 & 95.4 \\
\hline
\end{tabular}

2.2. Pathology. Sections $(4 \mathrm{~mm})$ were cut from the formalinfixed paraffin embedded blocks. One section was stained with Mayer's hematoxylin and eosin (H\&E). Histological slides were studied by light microscopy (Levenhuk D740T digital microscope, connected to a 5.1 MP camera, Russia). In the samples, the following indicators were evaluated by the visual analog way using a 200x magnification:

(i) The severity of lymphoid infiltration in tumor stroma (no and mild, the presence of weak diffuse infiltration or small focal infiltrates; severe, the presence of massive focal infiltrates)

(ii) The presence of DCs in the loose, fine-fibered connective tissue of the peritumoral stroma (none and single, no more than two in the field of view; multiple, more than two in the field of view)
2.3. Immunohistochemistry. For immunohistochemistry (IHC), 4- $\mu \mathrm{m}$ sections were dewaxed and hydrated. For antigen retrieval, the sections were boiling for $20 \mathrm{~min}$ in citrate buffer ( $\mathrm{pH} 6$ ) using an antigen retrieval PT module (Thermo Fisher Scientific Inc., Waltham, MA, USA). Endogenous peroxidase activity was blocked with $30 \mathrm{~mL} / \mathrm{L}$ hydrogen peroxide solution. Sections were then stained with the following antibodies: MAB959Hu21 monoclonal antibody to cluster of differentiation 34 (CD34), 1:100 dilution (Cloud-Clone Corp ${ }^{\circledR}$, Texas, USA); PAC719Hu01 polyclonal antibody to podoplanin (PDPN), 1:50 dilution (CloudClone Corp ${ }^{\circledR}$, Texas, USA); PAK089Hu01 polyclonal antibody to Snail homolog 1 (SNAI1), 1:100 dilution (CloudClone Corp ${ }^{\circledR}$, Texas, USA); PAA798Hu02 polyclonal antibody to hypoxia-inducible factor-1 alpha, 1:200 dilution (Cloud-Clone Corp ${ }^{\circledR}$, Texas, USA). The staining procedure was performed according to the manufacturers' protocols using an Autostainer 480 (Thermo Fisher Scientific Ltd., Vantaa, Finland). The visualization system included NovolinkTM Polymer Detection Kit (Leica Biosystems, Newcastle, UK). For the negative control sections, primary antibodies were replaced with phosphate-buffered saline and processed in the same manner.

The following indicators were evaluated in the samples:

(i) Microvessel density (MVD) was assessed in accordance with the international consensus on the methodology and criteria for quantitative evaluation of angiogenesis in human solid tumors [35]. MVD was determined by counting the number of CD34positive and podoplanin-positive normal microvessels (MVs) in five high-power (x400) fields in the selected "hotspot" areas, and the mean values of vessel counts were obtained. A single, countable microvessel was defined as any brown-stained endothelial cell (or cluster) clearly separated from the adjacent microvessels.

The number of different DCs, ADCs, and structures with partial endothelial lining was determined using a 200x magnification:

(i) The absolute number of different DCs and structures with partial endothelial lining was estimated in three fields of view in the selected "hotspot" areas, and the mean values of vessel counts were obtained

(ii) The relative number of different DCs, ADCs, and structures with partial endothelial lining was calculated using a visual analog method (none, single, and multiple, using 65 percentiles)

The following pathomorphological characteristics of tumor stromal and parenchymal component were evaluated:

(i) The presence of tumor emboli in CD34-positive and podoplanin-positive vessels (presence or absence).

(ii) The presence of fragmentation in the tumor solid component (presence or absence). The presence of fragmentation was evaluated positively when fibroblast-like tumor cells with nuclear expression of 
HIF- $1 \alpha$ and Snail were detected in the solid component of the tumor.

All sections were carefully and completely scanned by two of the authors (EM and ES) without knowledge of the clinical and pathological data.

2.4. Statistics. Statistical analysis was performed using the Statistica 10.0 software. The MVD and absolute number of DCs and structures with partial endothelial lining were demonstrated as mean $\pm \mathrm{SD}$. The normality of distribution was evaluated using the Kolmogorov-Smirnov test. Kruskal-Wallis or Mann-Whitney U nonparametric tests were used to compare the value of the quantitative and categorical data. The correlations between different data were evaluated using nonparametric Spearman's rank correlation or gamma correlation. Chi square tests were carried out to analyze the difference of distribution among the categorized data. The survival was analyzed by the Kaplan-Meier method. The logrank test was used to compare survival curves between subgroups of patients. A value of $p<0.05$ was considered statistically significant. The results and discussion may be presented separately, or in one combined section, and may optionally be divided into headed subsections.

\section{Results}

3.1. Morphological Features of Different Types of Tumor Vessels in Squamous Cervical Cancer. Based on the previously proposed classification of tumor MVs [32] in cervical cancer, the following types of tumor vessels were identified: normal MVs, DCs with normal endothelial lining, DCs with a weak expression of CD34, contact type DCs, MVs in the solid component of the tumor, ADCs, structures with partial endothelial lining, and lymphatic capillaries in the lymphoid or polymorphic cell infiltrates.

3.1.1. Normal Microvessels (MVs). These vessels were detected as capillaries with a diameter of 5-40 $\mu \mathrm{m}$ (Figure 1). In most cases, the vessels of this type had clear, even contours. Their endothelial lining was identified by cells with a flat hyperchromic nucleus. The expression of the CD34 marker in the cell cytoplasm was uniform and intense (Figure 1(a)). Capillaries with a diameter of $5-40 \mu \mathrm{m}$ were also detected when stained with antibodies to podoplanin (Figure 1(b)).

The MVD of CD34-positive normal MVs was 9.1 \pm 3.4 (from 4.2 to 17.1 in the field of view, median 8.2 ), and the MVD of podoplanin-positive normal MVs was $3.3 \pm 1.5$ (from 1.0 to 9.8 in the field of view, median 3.0). The difference in the density of blood and lymphatic MVs was statistically significant $(p<0.0001)$.

Dilated Capillaries (DCs). The vessels of this type had a diameter of 40 microns or more and were usually rounded or oval in shape. The expression of the CD34 marker in the cytoplasm of endothelial cells was uniform, and the vessel contours were clear and even. Depending on the characteristics of the vessels, three types of DCs were noted.
3.1.2. DCs with a Normal Endothelial Lining Formed by Cells with Flattened, Hyperchromic Nuclei. Among the described vessels, both regular oval shape vessels (Figure 2(a)) and vessels of irregular, angular shapes (Figure 2(b)) were observed. Both erythrocytes and leukocyte cells were detected in their lumen. The density of these vessels was $5.1 \pm 2.4$ (from 0 to 14 in the field of view, median 5.0). In $35.4 \%$ of cases, there were multiple DCs (5.5 or more in the field of view, 65 percentile). Some vessels of this type had been stained by antibodies to podoplanin (Figure 2(c)). Dilated lymphatic capillaries were located mainly in the peritumoral stroma. In addition, some DCs had a characteristic perivascular sheath (Figure 2(d)). Such perivascular sheaths were revealed in $92.2 \%$ of the examined cervical cancer samples. Podoplanin expression was not observed in these vessels.

3.1.3. DCs with a Weak Expression of CD34. In squamous cervical cancer, the single vessels of this type were detected in 21 cases (32.3\%), the multiple in 4 cases (6.2\%), and the vessels were absent in $40(61.5 \%)$. The DCs had a regular shape and were observed mainly in the loose, fine-fibered connective tissue of the peritumoral stroma; this had a characteristic cellular structure and was rich in cells with large, pale nuclei with a fine-netted chromatin structure (Figure 3(a)). In these vessels, the endothelial lining was also marked by cells with large, pale nuclei having a fine-netted chromatin structure. The CD34 marker was often weakly expressed in these cells (Figure 3(b)), and the expression of podoplanin was not observed, which indicates that the vessels of this type are blood vessels.

3.1.4. DCs of "Contact Type". A distinctive feature of these vessels was that their wall was in direct contact with tumor cells (Figure 4). The connective tissue layer between them was not determined (Figure 4(a)). Thin-walled vessels located in the intratumoral stroma were identified in 13 (20.3\%) cases. The average diameter of contact type DCs was $48.7 \pm 10.5 \mu \mathrm{m}$, and the expression of the CD34 marker was uniform, with a medium intensity. The contours of the vessels were clear and even (Figure 4(b)). Despite the fact that the contents in the lumen of contact-type DCs were most often absent or presented by leukocytes, no podoplanin expression was noted in them, indicating that these vessels were blood ones.

3.1.5. Capillaries in the Solid Tumor Component. The MVs located in the tumor solid component were detected in squamous cervical cancer (Figure 5). The vessels had clear, even contours and an even expression of CD34. Podoplanin expression was not observed in these vessels. We distinguished two types of these vessels:

(a) Capillaries Directly in Contact with Tumor Cells (Figure 5(a)). These vessels were detected in 35 $(54.8 \%)$ of the studied samples. The average diameter of these vessels was $64.3 \pm 12.7 \mu \mathrm{m}$, and the contents 


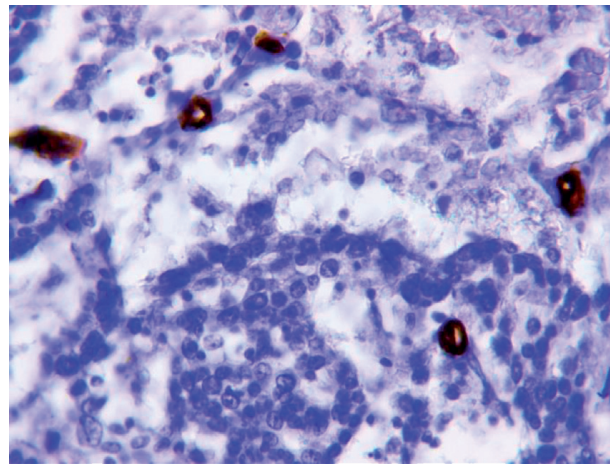

(a)

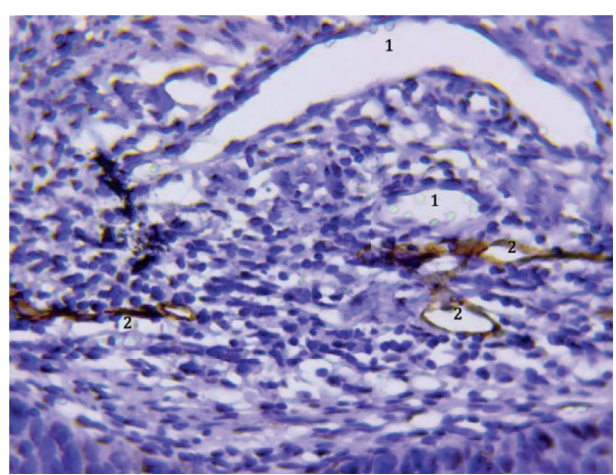

(b)

Figure 1: Normal microvessels. (a) Normal microvessels. Immunoperoxidase staining with antibody to CD34, x800. (b) Normal microvessels: blood capillaries (1); lymphatic capillaries (2). Immunoperoxidase staining with antibody to podoplanin, x800.

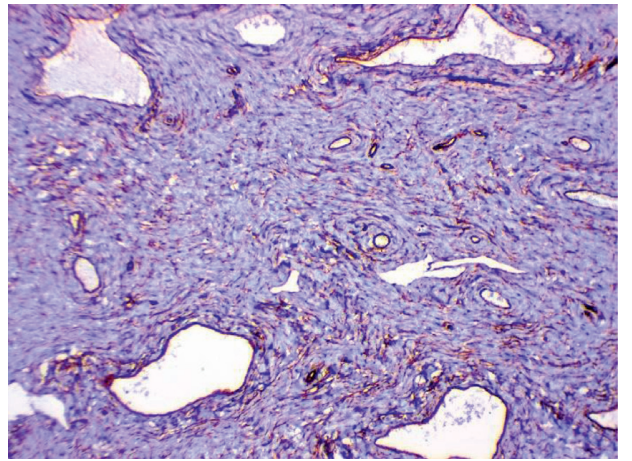

(a)

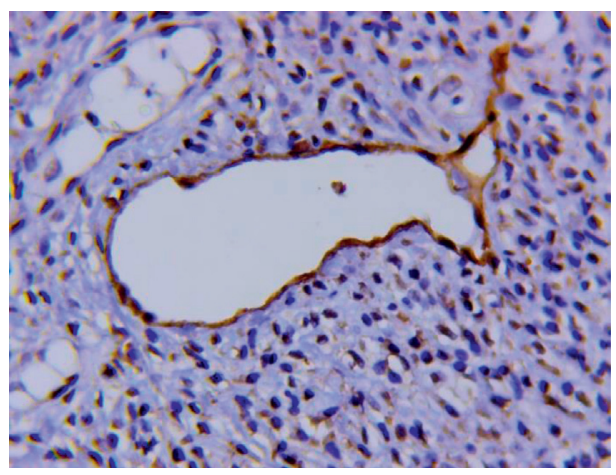

(c)

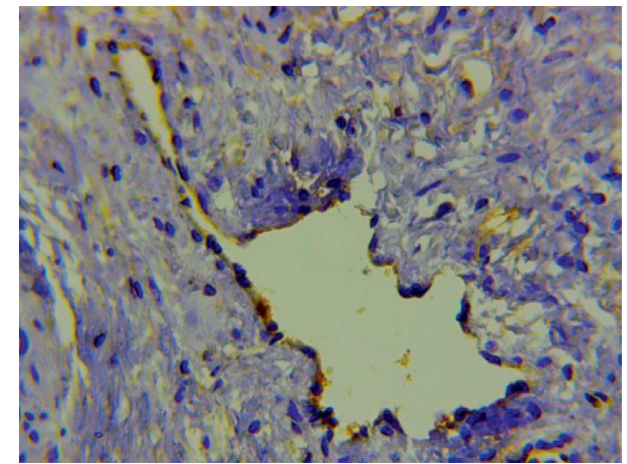

(b)

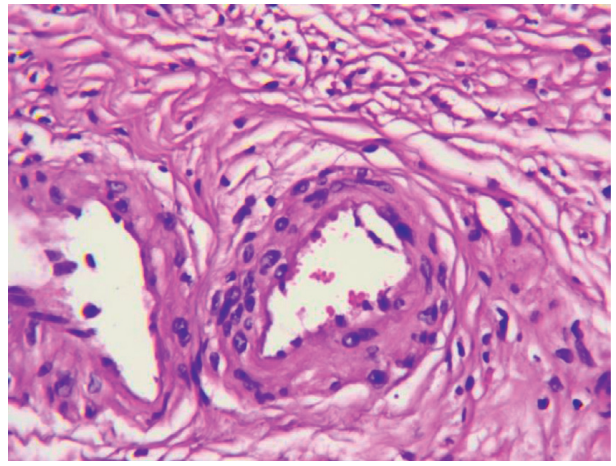

(d)

FIGURE 2: Dilated capillaries with a normal endothelial lining. (a) Dilated capillaries of regular oval shape. Immunoperoxidase staining with antibody to CD34, x800. (b) Dilated capillary of irregular angular shape. Immunoperoxidase staining with antibody to CD34, x800. (c) Dilated lymphatic capillary with a normal endothelial lining. Immunoperoxidase staining with antibody to podoplanin, x800. (d) Dilated capillaries with perivascular sheaths. H\&E staining, x800.

in the lumen of the vessels were most often absent or were presented by erythrocytes.

(b) Capillaries with Retraction of the Endothelium from Tumor Cells. These vessels were identified as collapsed capillaries with a linear form. The cytoplasm of the endothelial cells intensively expressed the marker CD34 (Figure 5(b)). These vessels were detected in $26(41.7 \%)$ of the studied samples. Moreover, in $12(18.8 \%)$ cases, both types of the described vessels were observed in the solid component of the tumor, with and without retraction of vessel walls from the tumor cells.

3.1.6. Atypical Dilated Capillaries (ADCs). As previously described [31,32], a critical difference between ADCs and other types of MVs existed in the chaotic arrangement of the endothelial cells that were irregular in shape (Figure 6). The cytoplasm of the lining cells was unevenly stained by CD34 and had an uneven surface with a number of protuberances, so that the contours of the vessels seemed to be indistinct 


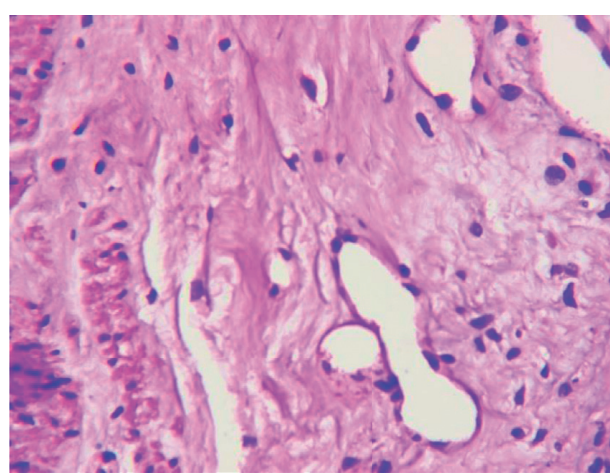

(a)

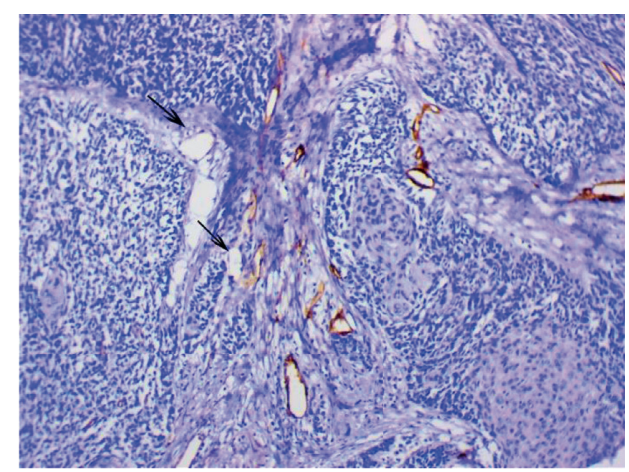

(b)

FIGURE 3: Dilated capillaries with a weak expression of CD34. (a) Dilated capillary of regular shape located in the loose, fine-fibered connective tissue of the peritumoral stroma. H\&E staining, x800. (b) A weak expression of CD34 in the dilated capillaries (arrows) located in the loose, fine-fibered connective tissue of the peritumoral stroma. Immunoperoxidase staining with antibody to CD34, x200.

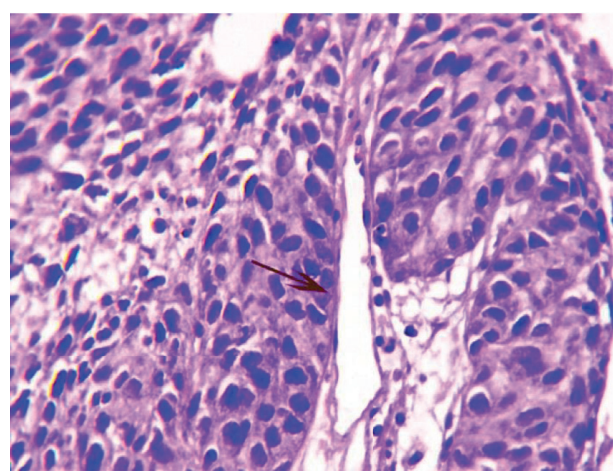

(a)

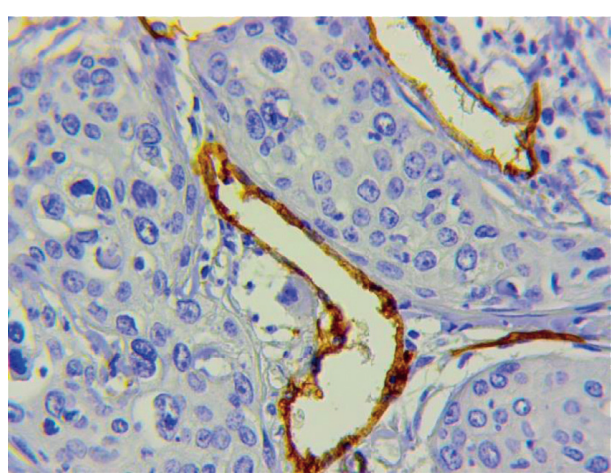

(b)

FIGURE 4: Dilated capillaries of "contact type". (a) Dilated capillary of contact type (arrow). H\&E staining, x800. (b) Dilated capillaries of contact type. Immunoperoxidase staining with antibody to CD34, x800.

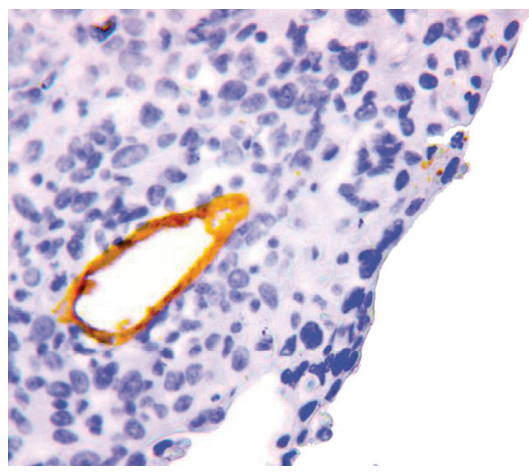

(a)

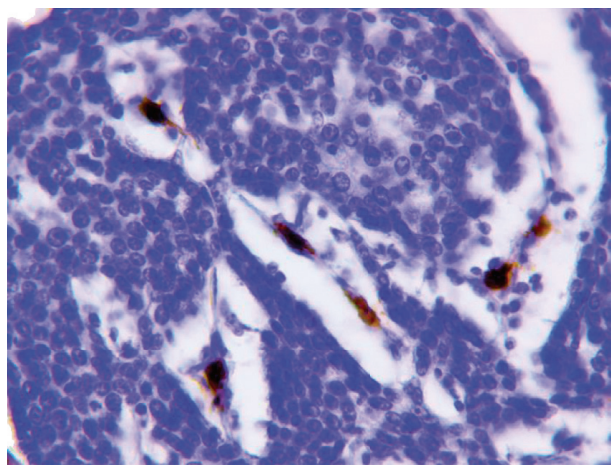

(b)

Figure 5: Capillaries in the solid tumor component. (a) Capillary in the solid tumor component directly in contact with tumor cells. Immunoperoxidase staining with antibody to CD34, x800. (b) Capillary in the solid tumor component with retraction of the endothelium from tumor cells. Immunoperoxidase staining with antibody to CD34, x800.

(Figure 6(a)). The density of ADCs was $1.9 \pm 1.9$ (from 0 to 9.7 in the field of view, median 1.5). Multiple ADCs (2 or more in the field of view, 65 percentile) were noted in $35.5 \%$ of cases. In cervical cancer, vessels of this type were significantly more frequently observed in the peritumoral than in the intratumoral stroma. As in gastric and breast cancer, tumor emboli and CD34-positive cells not associated with the vessel wall were often observed in their lumen (Figure 6(b)). Some ADCs exhibited positive staining with antibodies to podoplanin (Figure 6(c)). Almost all vessels 
with large complexes of tumor cells in their lumen were lymphatic vessels (Figure 6(d)).

3.1.7. The Structures with a Partial Endothelial Lining. As in gastric and breast cancer, structures with partial endothelial lining were revealed in cervical cancer (Figure 7). Their density was $2.8 \pm 1.8$ (from 0 to 8 in the field of view, median 2.6). Multiple structures with partial endothelial lining (3.3 and more in the field of view, 65 percentile) were detected in $35.4 \%$ of samples. Their characteristic feature was the chaotic arrangement of the endothelial cells with an irregular shape, uneven contours, and an uneven expression of CD34 and podoplanin markers. Analysis showed that in cervical cancer, $3 / 4$ of structures with partial endothelial lining were positive when stained with antibodies to podoplanin. A more detailed analysis made it possible to distinguish two types of described structures:

(a) Structures with Partial Endothelial Lining Associated with the Retraction of Tumor Cells from the Underlying Stroma (Figure 7(a)). In the lumen of these structures, large or small complexes of tumor cells have always been observed. In most cases, the structures were detected in peritumoral stroma and their endothelial lining was positive when stained with antibodies to podoplanin. When their present, the structures without endothelial lining and vessels with complexes of tumor cells in their lumen were also often observed in the tumor stroma. We believe that structures without endothelial lining correspond to the previously described phenomenon of tumor stroma retraction [36].

(b) Structures with Partial Endothelial Lining Which Were Not Associated with the Retraction of Tumor Cells from the Underlying Stroma (Figure 7(b)). These structures were located mainly in the peritumoral stroma and often had a linear or irregular shape. We believe that the formation of these structures may be associated with edema and inflammatory changes in the surrounding tissues.

3.1.8. Lymphatic Vessels in Lymphoid and Polymorphic Cell Infiltrates of Tumor Stroma. In 37 (56.9\%) samples, lymphatic vessels were detected in the lymphoid and polymorphic cell infiltrates of tumor stroma; these vessels differed in the following features (Figure 8):

(i) The vessels had a very thin, sometimes slightly noticeable endothelial lining (Figure 8(a)).

(ii) Lymphocytes and other leukocyte cells were often observed in their lumen (Figure 8(b)). Accumulations of cells with fragmentary (point) expression of markers and the presence of ordinary lymphatic capillaries were often observed in lymphoid infiltrates, which probably reflects different stages of the formation of lymphatic vessels of this type.

The described vessels and structures were usually not visualized when stained with Mayer hematoxylin and eosin.
(1) The Phenomenon of Fragmentation in Tumor Solid Component (Figures 9(a) and 9(b)). It should be noted that one of the interesting results of this study was the identification of the fragmentation phenomenon in the tumor solid component. The fragmentation phenomenon has been defined as the appearance of separate fibroblast-like cells with nuclear expression of HIF-1 $\alpha$ (Figure 9(c)) and Snail (Figure 9(d)) in the tumor solid component. Moreover, this phenomenon was associated with some types of tumor vessels as well as with clinical characteristics and prognosis of early cervical cancer.

(2) The Clinical Significance of Different Types of Tumor Vessels in Squamous Cervical Cancer. It was found that in early cervical cancer, the disease recurrence was associated with age $(p=0.004)$, histology ( $g a m m a=0.802 ; p=0.001)$, the depth of tumor invasion (gamma $=0.705 ; p=0.002$ ), the phenomenon of fragmentation in the tumor solid component (gamma $=0.786 ; p=0.0003$ ), and the presence of tumor emboli in CD34-positive vessels (gamma $=0.832$; $p=0.00003)$ and podoplanin-positive vessels (gamma $=0.968 ; p=0.0003$ ). The recurrence of cervical cancer was observed significantly more often in patients who were under 35 years of age $(p=0.02)$, had squamous cell keratinous carcinoma $(p=0.03)$, had a depth of tumor invasion of $10 \mathrm{~mm}$ or more $(p=0.02)$, whose histology results showed the presence of fragmentation phenomenon $(p=0.01)$, and the presence of tumor emboli in CD34positive vessels $(p=0.004)$ and podoplanin-positive vessels $(p=0.009)$. The frequency of cervical cancer recurrence depending on the disease clinical and pathological characteristics is presented in Table 2 .

The absence of correlations between stage and disease recurrence is most likely due to the fact that only patients with cervical cancer stages I-IIA were included in the study, and in whom the prognosis of the disease had been determined, firstly, by the biological characteristics of the tumor and sensitivity to adjuvant therapy. Thus, considering the above, the clinical significance of different types of tumor MVs and structures with partial endothelial lining was evaluated in line with these prognostic factors.

The analysis showed that DCs with a weak expression of CD34, "contact type" DCs, capillaries in the tumor solid component, and lymphatic vessels in the lymphoid and polymorphic cell infiltrates of the tumor stroma are the most significant factors in terms of cervical cancer prognosis.

The gamma correlation coefficient test (gamma) showed that the presence of DCs with a weak expression of CD34 correlated with stage (gamma $=0.511 ; p=0.0005)$, histology $($ gamma $=0.657 ; p=0.00001), \quad$ grade $\quad($ gamma $=0.322$; $p=0.009$ ), the depth of tumor invasion (gamma $=0.735$; $p<0.0001$ ), the phenomenon of fragmentation in the tumor solid component (gamma $=0.750 ; p=0.000004$ ), and the presence of tumor emboli in CD34-positive vessels (gamma $=0.543 ; p=0.0004)$ and podoplanin-positive vessels (gamma $=0.451 ; p=0.005$ ), as well as with the cervical cancer recurrence (gamma $=0.769 ; p=0.0005$ ). Data on the presence of DCs with a weak expression of CD34 depending 


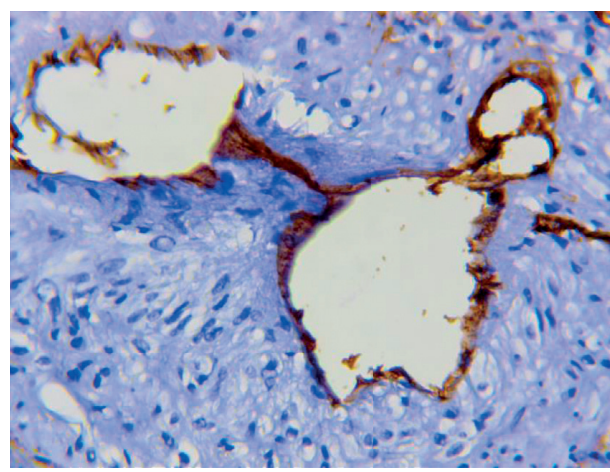

(a)

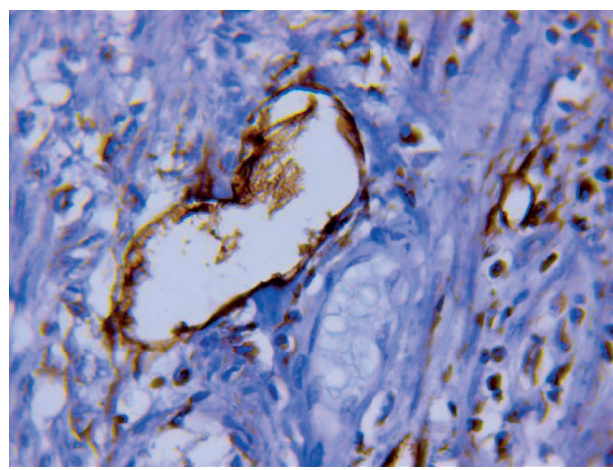

(c)

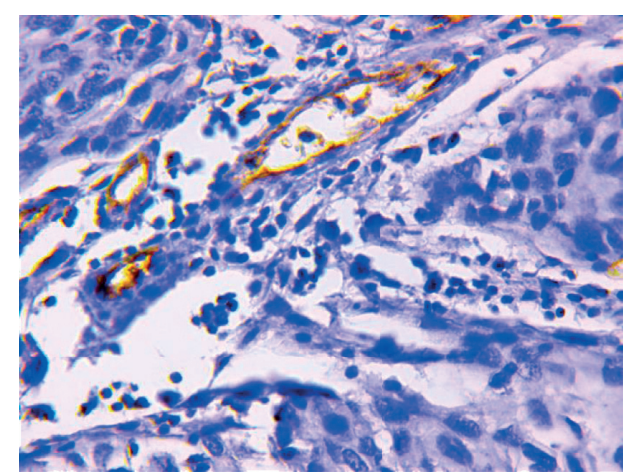

(b)

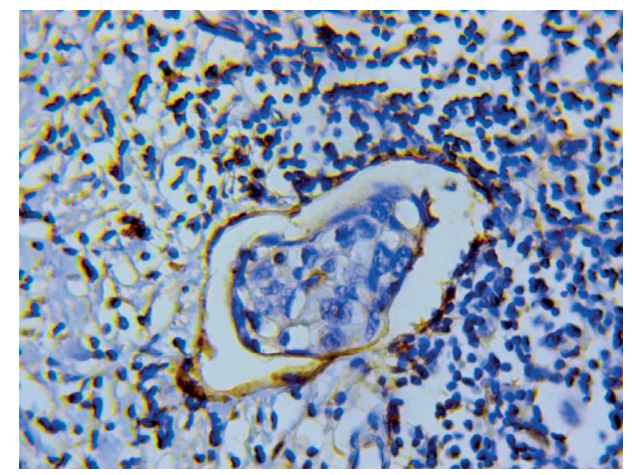

(d)

Figure 6: Atypical dilated capillaries. (a) Atypical dilated capillary in the peritumoral stroma. Immunoperoxidase staining with antibody to CD34, x800. (b) Atypical dilated capillary with CD34-positive cells in the lumen. Immunoperoxidase staining with antibody to CD34, x800. (c) Dilated lymphatic capillary with a chaotic arrangement of the endothelial cells. Immunoperoxidase staining with antibody to podoplanin, x800. (d) Dilated lymphatic capillary with a chaotic arrangement of the endothelial cells and a large complex of tumor cells in the lumen. Immunoperoxidase staining with antibody to podoplanin, x800.

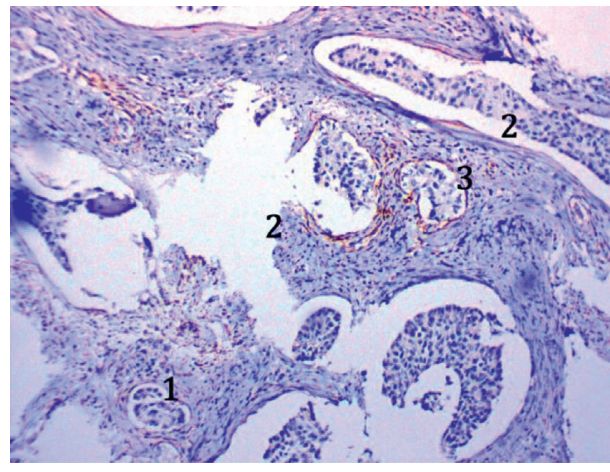

(a)

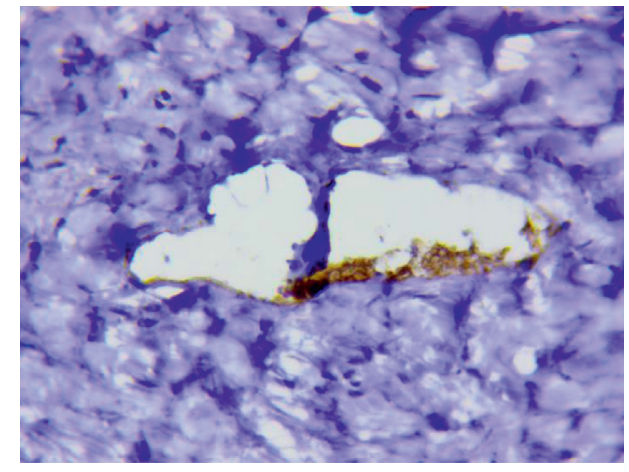

(b)

FIGURE 7: Structures with partial endothelial lining. (a) Structures with partial endothelial lining associated with the retraction of tumor cells from the underlying stroma: phenomenon of tumor stroma retraction (1), structures with partial endothelial lining (2), and lymphatic vessel with a large tumor embolus in the lumen (3). Immunoperoxidase staining with the antibodies to podoplanin, x200. (b) Structures with partial endothelial lining which were not associated with the retraction of tumor cells from the underlying stroma. Immunoperoxidase staining with the antibodies to podoplanin, $\mathrm{x} 800$.

on the clinical and the pathological cervical cancer characteristics and disease prognosis are presented in Table 3.

The depth of tumor invasion was $3.7 \pm 3.8 \mathrm{~mm}$, $6.8 \pm 5.1 \mathrm{~mm}$, and $12.5 \pm 2.9 \mathrm{~mm}$ in the absence of DCs with weak CD34 expression, single and multiple ones, respectively $(p=0.04)$.
The presence of contact type DCs correlated with stage (gamma $=0.641 ; p=0.0007), \quad$ histology $\quad($ gamma $=0.642$; $p=0.02$ ), grade (gamma $=0.249 ; p=0.05)$, the depth of tumor invasion (gamma $=0.700 ; p=0.00002$ ), the phenomenon of fragmentation in the tumor solid component (gamma $=0.578 ; p=0.003$ ), and the presence of tumor 


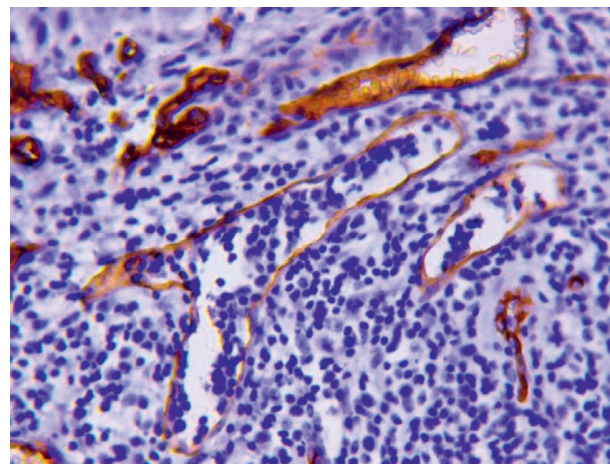

(a)

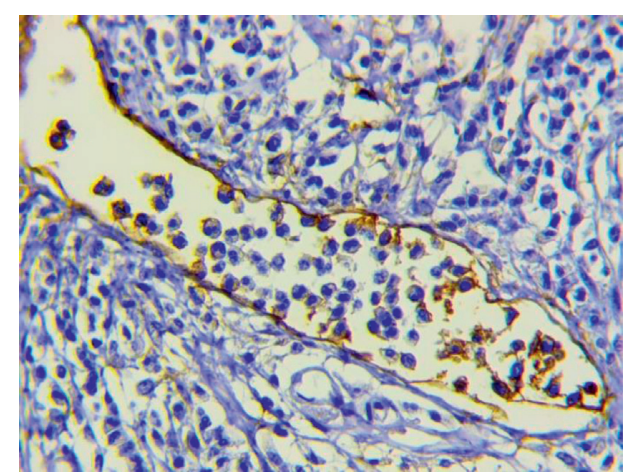

(b)

FIGURE 8: Lymphatic vessels in lymphoid and polymorphic cell infiltrates of tumor stroma. (a) Clump of lymphocytes in the lumen of thinwalled capillary located in the focal lymphoid infiltrate. Immunoperoxidase staining with the antibodies to CD34, x800. (b) Leukocyte cells in the lumen of thin-walled capillary. Some cells with fragmentary (point) expression of podoplanin. Immunoperoxidase staining with the antibodies to podoplanin, $\mathrm{x} 800$.

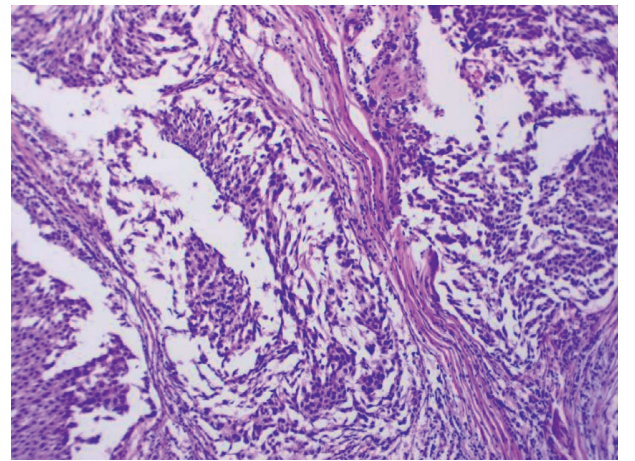

(a)

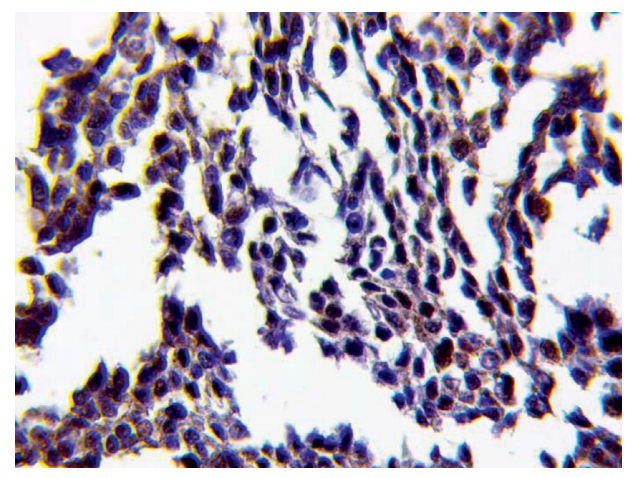

(c)

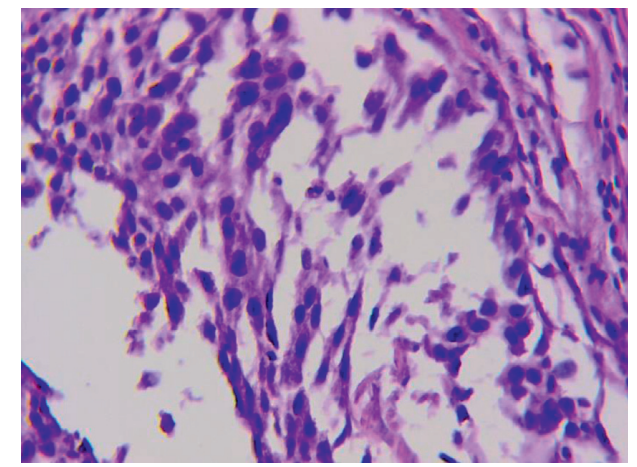

(b)

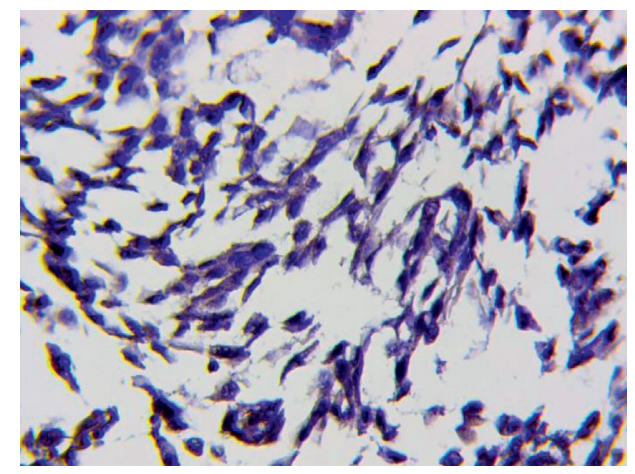

(d)

Figure 9: The fragmentation phenomenon in the tumor solid component. (a) The phenomenon of fragmentation in the tumor solid component. H\&E staining, $\mathrm{x} 200$. (b) Separate fibroblast-like cells in the tumor solid component. H\&E staining, x800. (c) Nuclear expression of HIF-1a in separate fibroblast-like cells in the tumor solid component. Immunoperoxidase staining with the antibodies to HIF-1a, x800. (d) Nuclear expression of Snail in separate fibroblast-like cells in the tumor solid component. Immunoperoxidase staining with the antibodies to Snail, $\mathrm{x} 800$.

emboli in CD34-positive vessels $\quad($ gamma $=0.686$; $p=0.00003)$ and podoplanin-positive vessels (gamma $=0.563 ; p=0.004$ ), as well as with the cervical cancer recurrence (gamma $=0.893 ; p<0.0001)$. Data on the presence of contact type DCs depending on the clinical and the pathological cervical cancer characteristics and disease prognosis are presented in Table 4.
The depth of tumor invasion was $4.1 \pm 3.3 \mathrm{~mm}$, $8.6 \pm 5.6 \mathrm{~mm}$, and $13.0 \pm 4.7 \mathrm{~mm}$ in the absence of contact type" DCs, single and multiple ones, respectively $(p=0.02)$.

The presence of the capillaries in the tumor solid component correlated with stage (gamma $=0.607$; $p=0.0007)$, histology (gamma $=0.540 ; p=0.0001)$, grade 
TABLE 2: The frequency of cervical cancer recurrence depending on the disease clinical and pathological characteristics.

\begin{tabular}{|c|c|c|c|c|c|}
\hline \multirow{3}{*}{ Clinical and pathological data } & \multicolumn{4}{|c|}{ Cervical cancer recurrence } & \multirow{3}{*}{$p$} \\
\hline & \multicolumn{2}{|c|}{ Absence } & \multicolumn{2}{|c|}{ Presence } & \\
\hline & $n$ & $\%$ & $n$ & $\%$ & \\
\hline \multicolumn{6}{|l|}{ Age (years) } \\
\hline$<35$ & 4 & 23.5 & 13 & 76.5 & $0.02^{*}$ \\
\hline $35-44$ & 1 & 3.1 & 31 & 96.9 & \\
\hline$\geq 45$ & 0 & 0 & 15 & 100.0 & \\
\hline \multicolumn{6}{|l|}{ Stages } \\
\hline IA & 1 & 3.6 & 27 & 96.4 & 0.33 \\
\hline IB & 4 & 12.9 & 27 & 87.1 & \\
\hline IIA & 0 & 0 & 5 & 100.0 & \\
\hline \multicolumn{6}{|l|}{ Histology } \\
\hline Squamous cell keratinous carcinoma & 4 & 18.2 & 18 & 81.8 & $0.03^{*}$ \\
\hline Squamous cell nonkeratinous carcinoma & 1 & 2.4 & 41 & 97.6 & \\
\hline \multicolumn{6}{|l|}{ Grade } \\
\hline G1 & 46 & 95.8 & 2 & 4.2 & 0.14 \\
\hline $\mathrm{G} 2$ & 7 & 77.8 & 2 & 22.2 & \\
\hline G3 & 6 & 85.7 & 1 & 14.3 & \\
\hline \multicolumn{6}{|l|}{ Depth of tumor invasion } \\
\hline$<10 \mathrm{~mm}$ & 1 & 2.3 & 42 & 97.7 & $0.02^{*}$ \\
\hline$\geq 10 \mathrm{~mm}$ & 4 & 19.1 & 17 & 80.9 & \\
\hline \multicolumn{6}{|l|}{ Fragmentation phenomenon } \\
\hline Absence & 2 & 3.9 & 50 & 96.1 & $0.01^{*}$ \\
\hline Presence & 3 & 25.0 & 9 & 75.0 & \\
\hline \multicolumn{6}{|l|}{ Tumor emboli in CD34-positive vessels } \\
\hline Absence & 0 & 0 & 33 & 100.0 & $0.004^{*}$ \\
\hline Presence & 5 & 22.7 & 17 & 77.3 & \\
\hline \multicolumn{6}{|l|}{ Tumor emboli in podoplanin-positive vessels } \\
\hline Absence & 0 & 0 & 32 & 100.0 & $0.009^{*}$ \\
\hline Presence & 5 & 21.7 & 18 & 78.2 & \\
\hline Depth of tumor invasion & & & & & $0.01^{*}$ \\
\hline
\end{tabular}

(gamma $=0.468 ; p=0.0001)$, the depth of tumor invasion (gamma $=0.826 ; p<0.00001)$, the phenomenon of fragmentation in the tumor solid component (gamma $=0.516$; $p=0.01$ ), and the presence of tumor emboli in CD34positive vessels (gamma $=0.656 ; p=0.00003$ ), as well as with the cervical cancer recurrence (gamma $=0.739$; $p=0.007)$. Data on the presence of the capillaries in the tumor solid component depending on the clinical and the pathological cervical cancer characteristics and disease prognosis are presented in Table 5.

The depth of tumor invasion was $3.4 \pm 3.4 \mathrm{~mm}$ and $8.0 \pm 5.4 \mathrm{~mm}$ in the absence and the presence of these vessels, respectively $(p=0.001)$.

The presence of the lymphatic vessels in lymphoid and polymorphic cell infiltrates correlated with stage (gamma $=0.517 ; p=0.0005)$, histology $\quad($ gamma $=0.538$; $p=0.0005$ ), the depth of tumor invasion (gamma $=0.708$; $p<0.00001)$, the phenomenon of fragmentation in the tumor solid component (gamma $=0.811 ; p=0.000001$ ), and the presence of tumor emboli in the podoplanin-positive vessels (gamma $=0.762 ; p=0.0001$ ). Data on the presence of these lymphatic vessels depending on the clinical and the pathological cervical cancer characteristics and disease prognosis are presented in Table 6.
The depth of tumor invasion was $4.3 \pm 4.2 \mathrm{~mm}$ and $10.0 \pm 4.7 \mathrm{~mm}$ in the absence and the presence of these vessels, respectively $(p=0.001)$. No association of the number of vessels of this type with the presence of cervical cancer recurrence was revealed.

The number of structures with partial endothelial lining that was associated with the retraction of tumor cells from the underlying stroma, which was significantly more in cases when the depth of tumor invasion was $10 \mathrm{~mm}$ or more $(p=0.003)$. No correlation of other types of tumor vessels with clinical characteristics and cervical cancer prognosis was noted.

It is important to note that the presence and quantity of the described MVs was interconnected. Moreover, "contact type" DCs correlated significantly with all types of vessels: with the presence of DCs with a weak expression of CD34 (gamma $=0.935 ; p<0.000001$ ), with the presence of capillaries in the tumor solid component (gamma $=0.736$; $p=0.00005$ ), and with the number of the lymphatic vessels in the lymphoid and polymorphic cell infiltrates of tumor stroma (gamma $=0.741 ; p=0.00006)$. DCs with a weak expression of CD34 also correlated with the presence of capillaries in the solid tumor component (gamma $=0.528$; $p=0.001$ ) and the number of the lymphatic vessels in the 
TABLE 3: The presence of DCs with a weak expression of CD34 depending on the clinical and the pathological cervical cancer characteristics and disease prognosis.

\begin{tabular}{|c|c|c|c|c|c|}
\hline \multirow{3}{*}{ Indicators } & \multicolumn{4}{|c|}{ Dilated capillaries with weakly expression of CD34 } & \multirow{3}{*}{$p$} \\
\hline & \multicolumn{2}{|c|}{ Absence } & \multicolumn{2}{|c|}{ Presence } & \\
\hline & $n$ & $\%$ & $n$ & $\%$ & \\
\hline \multicolumn{6}{|l|}{ Age (years) } \\
\hline$<35$ & 10 & 55.6 & 8 & 44.4 & 0.45 \\
\hline $35-44$ & 8 & 53.3 & 7 & 46.7 & \\
\hline$\geq 45$ & 22 & 68.7 & 10 & 31.3 & \\
\hline \multicolumn{6}{|l|}{ Stages } \\
\hline IA & 23 & 82.1 & 5 & 17.9 & $0.008^{*}$ \\
\hline $\mathrm{IB}$ & 14 & 43.8 & 18 & 56.2 & \\
\hline IIA & 3 & 60.0 & 2 & 40.0 & \\
\hline \multicolumn{6}{|l|}{ Histology } \\
\hline Squamous cell keratinous carcinoma & 32 & 74.4 & 11 & 26.6 & $0.008^{*}$ \\
\hline Squamous cell nonkeratinous carcinoma & 8 & 36.4 & 14 & 63.6 & \\
\hline \multicolumn{6}{|l|}{ Grade } \\
\hline G1 & 34 & 69.4 & 15 & 30.6 & $0.05^{*}$ \\
\hline G2 & 4 & 44.4 & 5 & 56.6 & \\
\hline G3 & 2 & 28.6 & 5 & 71.4 & \\
\hline \multicolumn{6}{|l|}{ Depth of tumor invasion } \\
\hline$<10 \mathrm{~mm}$ & 33 & 75.0 & 11 & 25.0 & $0.0007^{*}$ \\
\hline$\geq 10 \mathrm{~mm}$ & 7 & 33.3 & 14 & 66.7 & \\
\hline \multicolumn{6}{|l|}{ Fragmentation phenomenon } \\
\hline Absence & 37 & 69.8 & 16 & 30.2 & $0.001^{*}$ \\
\hline Presence & 3 & 25.0 & 9 & 75.0 & \\
\hline \multicolumn{6}{|l|}{ Tumor emboli in CD34-positive vessels } \\
\hline Absence & 23 & 69.7 & 10 & 30.3 & 0.13 \\
\hline Presence & 10 & 43.5 & 13 & 56.5 & \\
\hline \multicolumn{6}{|l|}{ Tumor emboli in podoplanin-positive vessels } \\
\hline Absence & 25 & 71.4 & 10 & 28.6 & 0.13 \\
\hline Presence & 14 & 48.3 & 15 & 51.7 & \\
\hline \multicolumn{6}{|l|}{ Recurrence } \\
\hline Absence & 37 & 64.9 & 20 & 35.1 & $0.004^{*}$ \\
\hline Presence & 1 & 20.0 & 4 & 80.0 & \\
\hline
\end{tabular}

lymphoid and polymorphic cell infiltrates of tumor stroma (gamma $=0.706 ; p=0.0002$ ). In turn, the presence of capillaries in the solid tumor component correlated with the number lymphatic vessels in the lymphoid and polymorphic cell infiltrates of tumor stroma (gamma $=0.546 ; p=0.007)$.

(3) Different Types of Tumor Microvessels and Prognosis of Stage I-IIA Cervical Cancer. As noted above, in $5(7.7 \%)$ patients, from 5 to 43 months after the completion of treatment, the recurrence of cervical cancer was diagnosed. Local recurrence was detected in 2 patients, systemic recurrence in 2 patients, and local and systemic relapse in 1 patient. All patients with cervical cancer recurrence died in the period from 12 to 36 months after end of treatment. Data on the 5-year relapse-free survival (RFS) depending on cervical cancer clinical and pathological characteristics and the presence of different types of tumor MVs are presented in Table 7.

For patients with early cervical cancer, it is of fundamental importance to assess the feasibility of adjuvant treatment and to predict its effectiveness. For this purpose, we compared the clinical and pathological characteristics of cervical cancer and the number of different types of tumor MVs in three groups of patients with stage IB-IIA. In group 1 , there were 11 patients without radiation therapy and without relapse, in group 2, there were 21 patients who received radiation therapy and without cervical cancer recurrence, and in group 3-4, there were patients who received radiation therapy and with cervical cancer recurrence. $\mathrm{Re}$ spectively, in groups 1, 2, and 3, there were $18.2 \%, 28.6 \%$, and $75 \%$ of patients under 35 years of age $(p=0.10) ; 54.6 \%$, $47.6 \%$, and $75 \%$ with squamous cell keratinous carcinoma ( $p=0.58) ; 36.4 \%, 47.6 \%$, and $100 \%$ of cases with a depth of tumor invasion of $10 \mathrm{~mm}$ or more $(p=0.09) ; 27.3 \%, 14.3 \%$, and $75 \%$ with the presence of fragmentation phenomenon in the tumor solid component $(p=0.04)) ; 54.6 \%, 47.6 \%$, and $100 \%$ with the presence of DCs with a weak expression of CD34 ( $p=0.15) ; 9.1 \%, 28.6 \%$, and $100 \%$ with the presence of "contact type" DCs $(p=0.003) ; 45.5 \%, 42.9 \%$, and $100 \%$ with the presence of capillaries in the tumor solid component ( $p=0.1$ ); and $23.7 \%, 19.1 \%$, and $50 \%$ of cases with the presence of lymphatic vessels in the lymphoid and polymorphic cell infiltrates of tumor stroma $(p=0.41)$. Interestingly, a combination of the phenomenon of 
TABle 4: The presence of contact type DCs depending on the clinical and the pathological cervical cancer characteristics and disease prognosis.

\begin{tabular}{|c|c|c|c|c|c|}
\hline \multirow{3}{*}{ Indicators } & \multicolumn{4}{|c|}{ "Contact type" dilated capillaries } & \multirow{3}{*}{$p$} \\
\hline & \multicolumn{2}{|c|}{ Absence } & \multicolumn{2}{|c|}{ Presence } & \\
\hline & $n$ & $\%$ & $n$ & $\%$ & \\
\hline \multicolumn{6}{|l|}{ Age (years) } \\
\hline$<35$ & 14 & 77.8 & 4 & 22.2 & 0.55 \\
\hline $35-44$ & 13 & 86.7 & 2 & 13.3 & \\
\hline$\geq 45$ & 24 & 77.4 & 7 & 22.6 & \\
\hline \multicolumn{6}{|l|}{ Stages } \\
\hline IA & 26 & 96.3 & 1 & 3.7 & 0.14 \\
\hline $\mathrm{IB}$ & 21 & 65.6 & 11 & 34.4 & \\
\hline IIA & 4 & 80.0 & 1 & 20.0 & \\
\hline \multicolumn{6}{|l|}{ Histology } \\
\hline Squamous cell keratinous carcinoma & 36 & 85.7 & 6 & 14.3 & 0.29 \\
\hline Squamous cell nonkeratinous carcinoma & 15 & 68.2 & 7 & 31.8 & \\
\hline \multicolumn{6}{|l|}{ Grade } \\
\hline G1 & 41 & 85.4 & 7 & 14.6 & $0.04^{*}$ \\
\hline G2 & 6 & 66.7 & 3 & 33.3 & \\
\hline G3 & 4 & 57.1 & 3 & 42.9 & \\
\hline \multicolumn{6}{|l|}{ Depth of tumor invasion } \\
\hline$<10 \mathrm{~mm}$ & 39 & 90.7 & 4 & 9.3 & $0.007^{*}$ \\
\hline$\geq 10 \mathrm{~mm}$ & 12 & 57.1 & 9 & 42.9 & \\
\hline \multicolumn{6}{|l|}{ Fragmentation phenomenon } \\
\hline Absence & 44 & 84.6 & 8 & 15.4 & 0.09 \\
\hline Presence & 7 & 58.3 & 5 & 41.7 & \\
\hline \multicolumn{6}{|l|}{ Tumor emboli in CD34-positive vessels } \\
\hline Absence & 30 & 90.9 & 3 & 9.1 & $0.009^{*}$ \\
\hline Presence & 13 & 59.1 & 9 & 40.9 & \\
\hline \multicolumn{6}{|l|}{ Tumor emboli in podoplanin-positive vessels } \\
\hline Absence & 30 & 88.2 & 4 & 11.8 & 0.06 \\
\hline Presence & 20 & 68.9 & 9 & 31.1 & \\
\hline \multicolumn{6}{|l|}{ Recurrence } \\
\hline Absence & 48 & 85.7 & 8 & 14.3 & $0.0003^{*}$ \\
\hline Presence & 1 & 20.0 & 4 & 80.0 & \\
\hline
\end{tabular}

fragmentation in the tumor solid component and the presence of "contact type" DCs was observed in 3 of 4 (75.0\%) patients with cervical cancer recurrence and only 1 of $32(3.1 \%)$ patients without recurrence $(p=0.0001)$.

\section{Discussion}

Cervical cancer remains one of the most important issues in modern oncology that is related with both high morbidity and mortality $[2,3]$. A key condition for reducing mortality from cervical cancer is the diagnosis of the disease in the early stages. However, cervical cancer, even in the early stages, is characterized by an aggressive course, and early diagnosis does not always guarantee the success of the treatment. In this regard, the problems of accurately assessing the risk of cervical cancer recurrence and choosing the optimal treatment tactics have not lost their relevance.

It is important to emphasize that in early cervical cancer, the assessment of the risk of recurrence is of fundamental importance for deciding on the need for adjuvant therapy. Currently, this assessment is based mainly on the clinical and pathological characteristics of cervical cancer, such as age, stage, tumor size, histological type and depth of tumor invasion, positive surgical margins, the presence of metastases in the lymph nodes, the presence of parametric and perineural invasion, and some other factors [37-40]. Despite careful selection, in some patients, adjuvant therapy is not only ineffective but also leads to the development of severe complications $[9,10,12,13,41-44]$. In this regard, the problem of selecting patients with a low risk of disease recurrence, as well as with chemo- and radioresistant tumors, remains relevant and the search for new prognostic and predictive markers of cervical cancer has not lost its significance.

Angiogenesis is one of the key factors in tumor progression [23-26, 45, 46]. At present, assessment of its activity is considered as an important marker of disease prognosis and sensitivity to anticancer therapy [47, 48], including cervical cancer [14-16]. The participation of angiogenesis in tumor progression is due to the fact that, on the one hand, tumor vessels transport tumor cells to the lymphatic collectors and target organs. On the other hand, tumor vessels (that are defective both anatomically and functionally) are 
TABLE 5: The presence of the capillaries in the tumor solid component depending on the clinical and the pathological cervical cancer characteristics and disease prognosis.

\begin{tabular}{|c|c|c|c|c|c|}
\hline \multirow{3}{*}{ Indicators } & \multicolumn{4}{|c|}{ Capillaries in the tumor solid component } & \multirow{3}{*}{$p$} \\
\hline & \multicolumn{2}{|c|}{ Absence } & \multicolumn{2}{|c|}{ Presence } & \\
\hline & $n$ & $\%$ & $n$ & $\%$ & \\
\hline \multicolumn{6}{|l|}{ Age (years) } \\
\hline$<35$ & 8 & 44.4 & 10 & 55.5 & 0.31 \\
\hline $35-44$ & 21 & 65.6 & 11 & 34.4 & \\
\hline$\geq 45$ & 9 & 64.3 & 5 & 35.7 & \\
\hline \multicolumn{6}{|l|}{ Stages } \\
\hline IA & 21 & 77.8 & 6 & 22.2 & $0.02^{*}$ \\
\hline IB & 16 & 50.0 & 16 & 50.0 & \\
\hline IIA & 1 & 20.0 & 4 & 80.0 & \\
\hline \multicolumn{6}{|l|}{ Histology } \\
\hline Squamous cell keratinous carcinoma & 30 & 78.9 & 12 & 21.1 & $0.02^{*}$ \\
\hline Squamous cell nonkeratinous carcinoma & 8 & 36.4 & 14 & 63.6 & \\
\hline \multicolumn{6}{|l|}{ Grade } \\
\hline G1 & 45 & 91.8 & 4 & 8.2 & $0.0002^{*}$ \\
\hline G2 & 6 & 75.0 & 2 & 25.0 & \\
\hline G3 & 2 & 28.6 & 5 & 71.4 & \\
\hline \multicolumn{6}{|l|}{ Depth of tumor invasion } \\
\hline$<10 \mathrm{~mm}$ & 33 & 76.7 & 10 & 23.4 & $0.00005^{*}$ \\
\hline$\geq 10 \mathrm{~mm}$ & 5 & 23.8 & 16 & 76.2 & \\
\hline \multicolumn{6}{|l|}{ Fragmentation phenomenon } \\
\hline Absence & 34 & 64.2 & 19 & 35.8 & 0.09 \\
\hline Presence & 4 & 36.4 & 7 & 63.6 & \\
\hline \multicolumn{6}{|l|}{ Tumor emboli in CD34-positive vessels } \\
\hline Absence & 24 & 72.7 & 9 & 37.3 & $0.01^{*}$ \\
\hline Presence & 9 & 39.1 & 14 & 60.9 & \\
\hline \multicolumn{6}{|l|}{ Tumor emboli in podoplanin-positive vessels } \\
\hline Absence & 23 & 65.7 & 12 & 34.3 & 0.26 \\
\hline Presence & 15 & 51.7 & 14 & 48.3 & \\
\hline \multicolumn{6}{|l|}{ Recurrence } \\
\hline Absence & 35 & 62.5 & 21 & 37.5 & 0.06 \\
\hline Presence & 1 & 20.0 & 4 & 80.0 & \\
\hline
\end{tabular}

not able to adequately supply tumor cells with oxygen and nutrients. This enhances tumor hypoxia, which can lead to both necrotic changes in the tumor and to activation of epithelial-mesenchymal transformation (EMT) mechanisms that allow tumor cells to survive under conditions of hypoxia, as well as chemo- and radioresistance [17]. In addition, chemo- and radioresistance of malignant neoplasms can also be associated with vessel co-option or hijacking normal blood vessels by tumor cells [49].

It was established that the formation of new vessels is associated with the activation of various factors, amongst which a special role belongs to the vascular endothelial growth factor (VEGF), which is expressed by tumor and stromal cells. Of the 5 subtypes of the VEGF family proteins (VEGF-A, -B, -C, and -D, and placenta growth factor (PlGF)), VEGF-A is the key protein responsible for the proliferation, survival, and mobilization of endothelial progenitor cells from the bone marrow into the peripheral circulation. By binding to membrane tyrosine kinase receptors (VEGFR-1, -2, and -3), VEGF affects the development of new, and survival of immature, blood vessels [46]. Increased VEGF expression attracts monocytes and macrophages into the tumor stroma, which contributes to the activation of matrix metalloproteinases (MMPs) and cell adhesion molecules $[46,50,51]$, degradation of the intercellular matrix, and initiation of the processes of invasion, metastasis, and angiogenesis [52, 53].

To evaluate the activity of angiogenesis, researchers use various markers, including VEGF, main fibroblast growth factor (bFGF), MVD, and several others. In cervical cancer, an assessment of the prognostic significance of angiogenesis activity using these markers did not allow unambiguous results [14-16, 54]. In addition, a very limited number of publications related to the study of angiogenesis features in cervical cancer have been presented in PubMed and most of which were performed more than 10 years ago. Thus, 14 studies, dated 2000-2011, were included in a meta-analysis of Zhang et al. [16]. This showed that overexpression of VEGF or VEGF-C is significantly associated with poor survival outcome in cervical cancer patients and can be used as a prognostic and predictive marker. Similar results were obtained in a meta-analysis of Sun et al. [55].

Researchers have shown that VEGF-positive expression is associated with a higher risk of lymph node metastases in 
TABLE 6: The presence of lymphatic vessels in lymphoid and polymorphic cell infiltrate depending on the clinical and the pathological cervical cancer characteristics and disease prognosis.

\begin{tabular}{|c|c|c|c|c|c|}
\hline \multirow{3}{*}{ Indicators } & \multicolumn{4}{|c|}{$\begin{array}{l}\text { Lymphatic vessels in the tumor stroma lymphoid and } \\
\text { polymorphic cell infiltrates }\end{array}$} & \multirow{3}{*}{$p$} \\
\hline & \multicolumn{2}{|c|}{ No, single } & \multicolumn{2}{|c|}{ Multiple } & \\
\hline & $n$ & $\%$ & $n$ & $\%$ & \\
\hline \multicolumn{6}{|l|}{ Age (years) } \\
\hline$<35$ & 10 & 55.6 & 8 & 44.4 & 0.26 \\
\hline $35-44$ & 8 & 53.3 & 7 & 46.7 & \\
\hline$\geq 45$ & 24 & 75.0 & 8 & 25.0 & \\
\hline \multicolumn{6}{|l|}{ Stages } \\
\hline IA & 23 & 82.1 & 5 & 17.9 & 0.1 \\
\hline IB & 17 & 53.1 & 15 & 46.9 & \\
\hline IIA & 2 & 40.0 & 3 & 60.0 & \\
\hline \multicolumn{6}{|l|}{ Histology } \\
\hline Squamous cell keratinous carcinoma & 32 & 74.4 & 11 & 25.6 & $0.04^{*}$ \\
\hline Squamous cell nonkeratinous carcinoma & 10 & 45.5 & 12 & 55.5 & \\
\hline \multicolumn{6}{|l|}{ Grade } \\
\hline G1 & 42 & 85.7 & 7 & 14.3 & 0.57 \\
\hline G2 & 7 & 77.8 & 2 & 22.2 & \\
\hline G3 & 5 & 71.4 & 2 & 28.6 & \\
\hline \multicolumn{6}{|l|}{ Depth of tumor invasion } \\
\hline$<10 \mathrm{~mm}$ & 34 & 77.3 & 10 & 22.7 & $0.0004^{*}$ \\
\hline$\geq 10 \mathrm{~mm}$ & 8 & 38.1 & 13 & 61.9 & \\
\hline \multicolumn{6}{|l|}{ Fragmentation phenomenon } \\
\hline Absence & 48 & 90.6 & 5 & 9.4 & $0.002^{*}$ \\
\hline Presence & 6 & 50.0 & 6 & 50.0 & \\
\hline \multicolumn{6}{|l|}{ Tumor emboli in CD34-positive vessels } \\
\hline Absence & 29 & 87.9 & 4 & 12.1 & 0.09 \\
\hline Presence & 16 & 69.6 & 7 & 30.4 & \\
\hline \multicolumn{6}{|l|}{ Tumor emboli in podoplanin-positive vessels } \\
\hline Absence & 33 & 94.3 & 2 & 5.7 & $0.007^{*}$ \\
\hline Presence & 20 & 68.9 & 9 & 31.1 & \\
\hline \multicolumn{6}{|l|}{ Recurrence } \\
\hline Absence & 36 & 63.2 & 21 & 36.8 & 0.28 \\
\hline Presence & 3 & 60.0 & 2 & 40.0 & \\
\hline
\end{tabular}

cervical cancer. However, these results were observed only among Asian, Caucasian, and Chinese populations, but not among Korean or Japanese populations. A meta-analysis of $\mathrm{Hu}$ et al. included 13 studies dated 1997-2009 [15]. The authors noted that only MVD in the tumor, evaluated using factor VIII as an endothelial biomarker, was associated with long-term cervical cancer treatment results. When evaluating angiogenesis activity using antibodies to CD31, CD34, or CD105, correlations of MVD with cervical cancer prognosis were not revealed. In a study by Yani et al., the authors noted an increase in the level of VEGF and MVD in samples of squamous cell carcinoma compared with cervical inflammation and cervical intraepithelial neoplasia; however, there was no association of these markers with the stage of cervical cancer [56].

It should be noted that in the research mentioned above, the study of the prognostic significance of angiogenesis in cervical cancer was associated exclusively with a quantitative assessment of the expression of the various markers. Meanwhile, many modern studies indicate that vessels in tumors are heterogeneous and differ in origin, morphology, the degree of maturity, and sensitivity to anticancer therapy [57-60]. Thus, we previously studied the morphological features and clinical significance of different types of tumor vessels in gastric and breast cancer [31, 32]. We found that blood vessels differ not only in morphology, but also in clinical significance. As a result of this study, we identified 5 types of MVs and structures with endothelial lining: normal capillaries, DCs, ADCs, cavitary structures of type-1, and cavitary structures of type-2.

In breast and gastric cancer, the most significant prognostic factors were ADCs and structures with a partial endothelial lining (cavitary structures of type-1), which had similar morphological features, significantly correlated with each other $(p<0.00001)$ and were associated with the same disease characteristics. In gastric cancer, multiple ADCs and structures with partial endothelial lining were significantly more often observed at T3-4 $(p=0.001)$ and N2 stages $(p=0.001)$ and their presence was associated with a decrease in overall $(p=0.001)$ and relapse-free survival (RFS) $(p=0.0001)$. In breast cancer, the described vessels and structures were significantly more often observed in 
TABLE 7: 5-year relapse-free survival depending on cervical cancer clinical and pathological characteristics and the presence of different types of tumor vessels.

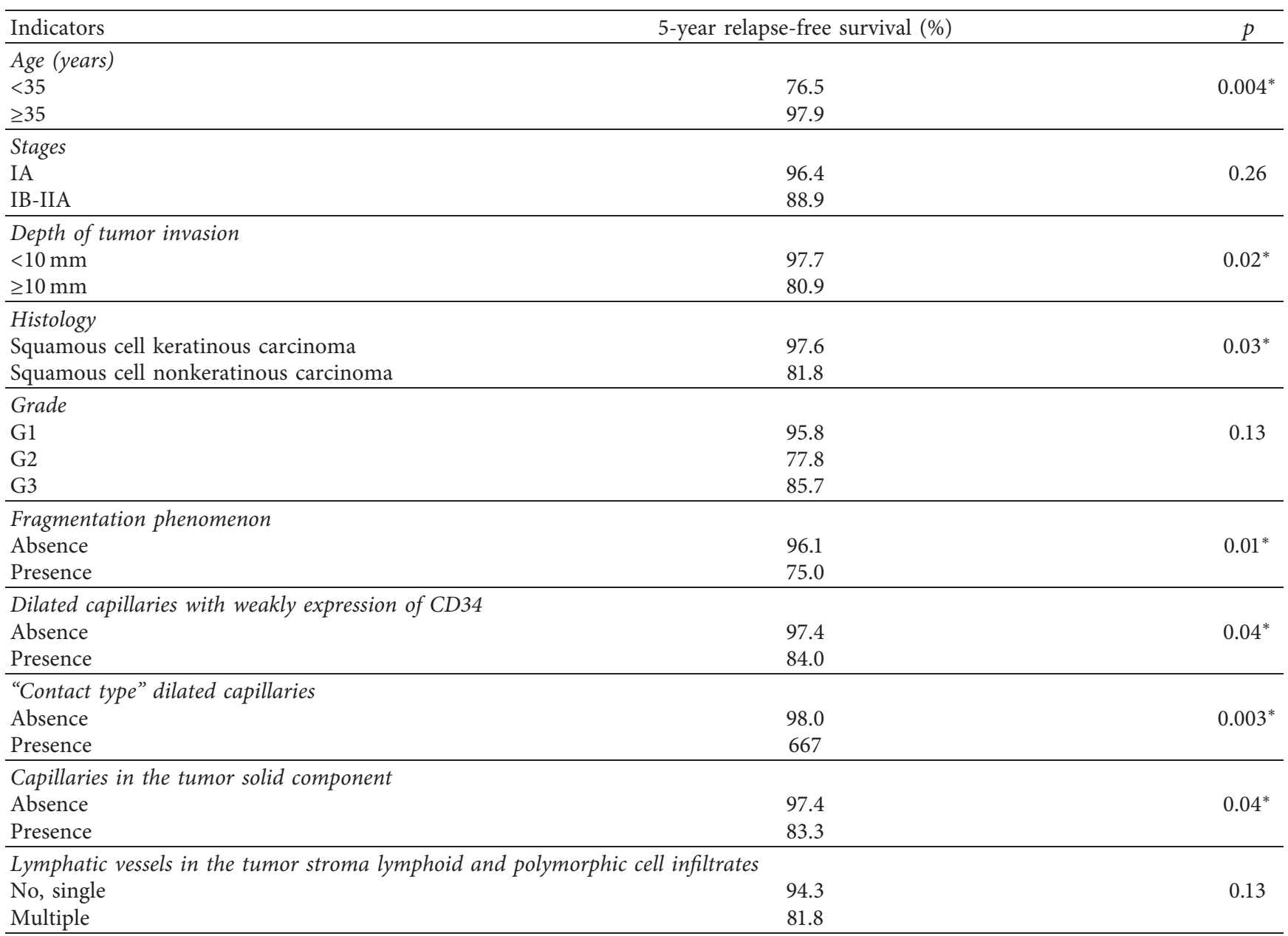

estrogen negative tumors $(p=0.03)$ and in the presence of tumor emboli in the vessels $(p=0.08)$. In breast cancer, there was also a correlation between the cavitary structures of type- 2 and a positive HER $2 /$ neu status $(p=0.008)$. These data indirectly indicated the general mechanisms of the formation of ADCs and structures with partial endothelial lining.

In this research, the object of the study was the features of morphology and clinical significance of different types of tumor vessels in early squamous cervical cancer. All patients at the first treatment stage underwent various surgery (various hysterectomy options were performed in $93.8 \%$ of cases), 29 (44.6\%) patients received adjuvant radiation therapy, and $3(4.6 \%)$ received adjuvant chemotherapy. In 5 (7.7\%) patients, in the period from 5 to 43 months after completion of treatment, the recurrence of cervical cancer was diagnosed. Given that only patients with I-IIA stages were included in the study, in whom the disease prognosis was determined primarily by the tumor biological characteristics and sensitivity to the adjuvant therapy, we first evaluated the clinical and pathological characteristics of cervical cancer associated with the development of disease recurrence. As a result of the analysis, it was found that cervical cancer recurrence was significantly more frequently observed in patients younger than 35 years $(p=0.02)$, with a tumor invasion depth of $10 \mathrm{~mm}$ or more $(p=0.02)$, in cases of squamous nonkeratinized cancer $(p=0.03)$, in the presence of fragmentation phenomenon in the solid component of the tumor $(p=0.01)$, as well as in the presence of tumor emboli in the blood $(p=0.004)$ and lymphatic vessels $(p=0.009)$. These data allowed us to evaluate the clinical significance of tumor vessels in early stage of squamous cervical cancer, taking into account not only the presence of disease recurrence, but also these prognostic factors.

A comparative analysis of the morphology of the different tumor vessels has allowed us to identify the vessels that we described earlier in gastric and breast cancer as well as to describe new vessels. In addition, we decided to change some vessel names to new ones, allowing us to more accurately characterize the features of the observed vessels and structures with endothelial lining. In particular, the cavitary structures of type-1 were renamed as the structures with partial endothelial lining, and cavitary structures of type-2 were renamed as DCs with weak expression of CD34. The use of antibodies to CD34 and podoplanin as markers made it possible to clarify the features of the morphology and 
localization of lymphatic vessels, to compare their number with the number of CD34-positive vessels as well as to evaluate the clinical significance of the lymphatic vessels in early cervical cancer. Summary data on the morphology of the described MVs and their correlations with clinical characteristics and prognosis of early cervical cancer are presented in Tables 8 and 9.

Analysis of the data presented in the summary tables allowed us to highlight some common features in morphology and clinical significance of different types of tumor vessels. In particular, the normal MVs and DCs with normal endothelial lining were localized both in intra- and in peritumoral stroma, were intensively stained with antibodies to CD34, and had clear, even contours. Some vessels of these types were positive when stained by antibodies to podoplanin, but the density of CD34-positive vessels was almost three times higher than the density of podoplanin-positive ones $(p<0.0001)$. No significant differences in the density of these vessels depending on the clinical and pathological characteristics and the prognosis of early cervical cancer were found.

A common morphological feature of ADCs and the structures with partial endothelial lining is that their endothelial lining was formed by chaotic located endothelial cells having an irregular shape and unevenly expressing the CD34 marker. Staining of the samples with antibodies to podoplanin demonstrated that the majority of ADCs and structures with partial endothelial lining located in the peritumoral stroma are related to the lymphatic vessels. In contrast to breast and gastric cancer, the correlations of ADCs and structures with partial endothelial lining with clinical characteristics and cervical cancer prognosis have not been established. Perhaps this is due to the fact that only patients with I-IIA stages of cervical cancer, having a favorable prognosis, were included in the study.

We previously suggested that the formation of tumor vessels can occur not only due to sprouting angiogenesis, vessel co-option, vasculogenic mimicry, intussusceptive angiogenesis, or vasculogenesis $[26,34,61,62]$, but also due to the formation of "cavitary" structures in the tumor stroma, being then lined by the endothelium and merged into the blood vessels of the organ [31, 32]. We hypothesized that there are two main mechanisms for the formation of such structures. The first mechanism can be associated with the abruption of tumor cells from their underlying foundation, and the second with the processes of formation and lysis of tumor stroma, which occur most actively at the border of tumor with the surrounding tissues.

We believe that this hypothesis is in good agreement with another assumption that tumor angiogenesis and vasculogenesis, in fact, mimic the processes of embryonic vasculogenesis $[63,64]$. It is known that during embryonic vasculogenesis, the formation of interstitial canals and gaps located in the mesenchyme precedes the formation of lymphatic and blood vessels. Tumor angiogenesis is also associated with remodeling of the extracellular matrix. Under the influence of matrix metalloproteinases, cleavage of the connective tissue matrix occurs with the formation of channels for growing vessels and vasculogenous mimicry [65]. Both in embryogenesis and in tumor growth, the stroma is directly involved in formation of channels, which determine the basis and direction of newly formed vessel growth [66]. It can be assumed that the cavitary type of angiogenesis, in principle, is a variant of postnatal vasculogenesis, where the role of channels and cracks can be played the cavitary structures formed as a result of retraction of tumor cells from the underlying stroma, the processes of formation, and lysis of the tumor stroma as well as tissue stratification as a result of edema or inflammation. Whether vessels formed in this way are functional and how they can be associated with the chemoand radioresistance of malignant neoplasms remains to be investigated.

The data in Table 9 show that only DCs with weak expression of CD34, DCs of contact type, intratumoral microvessels, and lymphatic vessels in the lymphoid and polymorphic cell infiltrates of tumor stroma were the most significant in terms of prognosis of early cervical cancer. It should be noted that DCs with weak expression of CD34 and DCs of contact type correlated with each other $(p<0.000001)$ were negative when stained by antibodies to podoplanin, and the contents in their lumen were absent or were presented by lymphoid cells. The weak staining of the endothelial cells with antibodies to CD34 and the presence of cells with large, pale nuclei having a fine-netted chromatin structure in endothelial lining may indirectly indicate that progenitor stem cells can take part in their formation. It is known that the earliest precursor cells are CD34 negative and, in the presence of relevant factors in the microenvironment, are able to differentiate into different cell lines, including into endothelial cells [67].

It can be assumed that the described vessels, creating a moderate hypoxic environment, can contribute to the survival of tumor cells due to the activation of EMT mechanisms. This assumption is indirectly confirmed by the correlation of DCs with a weak expression of CD34 with the fragmentation phenomenon in the tumor solid component $(p=0.001)$. In the presence of the fragmentation phenomenon, the tumor cells assumed an elongated fibroblast-like form and showed nuclear expression of HIF-1a and Snail. Cancer stem cells are known to represent the main pool of chemo- and radioresistant cells, and their high level in the tumor is associated with an unfavorable prognosis for a disease [68-70]. In our study, in patients receiving adjuvant radiation therapy, a combination of contact-type vessels and the fragmentation phenomenon was observed in 3 of $4(75 \%)$ patients with cervical cancer recurrence and only in 1 out of $32(3.1 \%)$ without cervical cancer recurrence $(p=0.0001)$. Given the small number of cervical cancer recurrences, the predictive significance of the described marker requires a more thorough examination.

Here, we also describe two new types of MVs that are correlated with prognostically significant clinical and pathological characteristics of early cervical cancer: capillaries in the tumor solid component and lymphatic vessels in 
TABLE 8: Summary data on the tumor microvessel morphology in squamous cervical cancer.

\begin{tabular}{|c|c|c|c|c|c|c|c|c|}
\hline & $\begin{array}{c}\text { Normal } \\
\text { microvessels }\end{array}$ & $\begin{array}{l}\text { DCs with a } \\
\text { normal } \\
\text { endothelial } \\
\text { lining }\end{array}$ & $\begin{array}{l}\text { DCs with a } \\
\text { weak } \\
\text { expression } \\
\text { of CD34 }\end{array}$ & $\begin{array}{c}\text { DCs of } \\
\text { contact type }\end{array}$ & $\begin{array}{l}\text { Capillaries } \\
\text { in the solid } \\
\text { tumor } \\
\text { component }\end{array}$ & $\begin{array}{l}\text { Atypical } \\
\text { dilated } \\
\text { capillaries }\end{array}$ & $\begin{array}{c}\text { The } \\
\text { structures } \\
\text { with a partial } \\
\text { endothelial } \\
\text { lining }\end{array}$ & $\begin{array}{l}\text { Lymphatic } \\
\text { vessels in } \\
\text { lymphoid and } \\
\text { polymorphic } \\
\text { cell infiltrates }\end{array}$ \\
\hline Localization & $\begin{array}{l}\text { In intra- and } \\
\text { peritumoral } \\
\text { stroma }\end{array}$ & $\begin{array}{c}\text { In intra- and } \\
\text { peritumoral } \\
\text { stroma }\end{array}$ & $\begin{array}{l}\text { Mainly in } \\
\text { peritumoral } \\
\text { stroma }\end{array}$ & $\begin{array}{c}\text { Mainly in } \\
\text { intratumoral } \\
\text { stroma }\end{array}$ & $\begin{array}{l}\text { In the solid } \\
\text { tumor } \\
\text { component }\end{array}$ & $\begin{array}{c}\text { In intra- and } \\
\text { peritumoral } \\
\text { stroma }\end{array}$ & $\begin{array}{l}\text { Mainly in } \\
\text { peritumoral } \\
\text { stroma }\end{array}$ & $\begin{array}{l}\text { Mainly in } \\
\text { peritumoral } \\
\text { stroma }\end{array}$ \\
\hline $\begin{array}{l}\text { Diameter } \\
(\mu \mathrm{m})\end{array}$ & $19.7 \pm 10.0$ & $101.9 \pm 52.2$ & $59.4 \pm 29.6$ & $48.7 \pm 10.5$ & Collapsed & $109.7 \pm 43.9$ & - & $85.2 \pm 33.3$ \\
\hline Shape & Regular & $\begin{array}{l}\text { Regular and } \\
\text { irregular }\end{array}$ & Regular & Regular & Linear & Irregular & Irregular & Regular \\
\hline Contours & Smooth & Smooth & Smooth & Smooth & Smooth & Uneven & Uneven & Smooth \\
\hline $\begin{array}{l}\text { Arrangement } \\
\text { of the } \\
\text { endothelial } \\
\text { cells }\end{array}$ & Normal & Normal & Normal & Normal & Normal & Chaotic & Chaotic & Normal \\
\hline $\begin{array}{l}\text { The severity of } \\
\text { CD34 } \\
\text { expression }\end{array}$ & Intensively & Intensively & Weakly & Moderately & Intensively & Intensively & Intensively & Moderately \\
\hline $\begin{array}{l}\text { Podoplanin } \\
\text { staining }\end{array}$ & Some positive & Some positive & Negative & Negative & Negative & Some positive & $\begin{array}{c}\text { Some } \\
\text { positive }\end{array}$ & All positive \\
\hline Content & $\begin{array}{c}\text { Erythrocytes, } \\
\text { white blood } \\
\text { cells }\end{array}$ & $\begin{array}{c}\text { Erythrocytes, } \\
\text { white blood } \\
\text { cells }\end{array}$ & Often absent & $\begin{array}{c}\text { Absent or } \\
\text { white blood } \\
\text { cells }\end{array}$ & - & $\begin{array}{c}\text { Absent, } \\
\text { erythrocytes, } \\
\text { white blood } \\
\text { cells }\end{array}$ & $\begin{array}{l}\text { Absent or } \\
\text { tumor mass }\end{array}$ & $\begin{array}{l}\text { Lymphocytes } \\
\text { and other } \\
\text { white blood } \\
\text { cells }\end{array}$ \\
\hline $\begin{array}{l}\text { Tumor emboli } \\
\text { in the lumen }\end{array}$ & Rarely & Rarely & Rarely & Rarely & Rarely & Often & Often & Rarely \\
\hline $\begin{array}{l}\text { CD34- } \\
\text { positive cells } \\
\text { in the lumen }\end{array}$ & Rarely & Rarely & Absent & Absent & Absent & Often & Often & Absent \\
\hline
\end{tabular}

TABLE 9: Summary data on the correlation of different types of tumor microvessels with clinical and morphological characteristics and prognosis of squamous cervical cancer.

\begin{tabular}{|c|c|c|c|c|c|c|c|c|}
\hline & $\begin{array}{c}\text { Normal } \\
\text { microvessels }\end{array}$ & $\begin{array}{l}\text { DCs with a } \\
\text { normal } \\
\text { endothelial } \\
\text { lining }\end{array}$ & $\begin{array}{l}\text { DCs with a } \\
\text { weak } \\
\text { expression of } \\
\text { CD34 }\end{array}$ & $\begin{array}{c}\text { DCs of } \\
\text { contact type }\end{array}$ & $\begin{array}{l}\text { Capillaries } \\
\text { in the tumor } \\
\text { solid } \\
\text { component }\end{array}$ & $\begin{array}{l}\text { Atypical } \\
\text { dilated } \\
\text { capillaries }\end{array}$ & $\begin{array}{l}\text { The } \\
\text { structures } \\
\text { with a partial } \\
\text { endothelial } \\
\text { lining }\end{array}$ & $\begin{array}{l}\text { Lymphatic } \\
\text { vessels in } \\
\text { lymphoid and } \\
\text { polymorphic } \\
\text { cell infiltrates }\end{array}$ \\
\hline Age & $=0.92$ & & & & & & $p=0.18$ & $p=0.13$ \\
\hline Stages & & & $p=0.00$ & $p=$ & $0007^{*}$ & & $p=$ & $5^{*}$ \\
\hline Histology & & & $p=0.00001^{*}$ & $p=0.02^{*}$ & $0001^{*}$ & & $p=$ & $.0005^{*}$ \\
\hline Grade & & & $p=0.009^{*}$ & & & & $p=$ & $01^{*}$ \\
\hline $\begin{array}{l}\text { Depth of tumor } \\
\text { invasion }\end{array}$ & $p=0.08$ & $p=0.55$ & $p=0.0001^{*}$ & $p=0.00002^{*}$ & $p=0.0001^{*}$ & $p=0.55$ & $p=0.06$ & $p=0.0004^{*}$ \\
\hline $\begin{array}{l}\text { Fragmentation } \\
\text { phenomenon }\end{array}$ & $p=0.11$ & $p=0.44$ & $p=0.000004^{*}$ & $p=0.003^{*}$ & $p=0.01^{*}$ & $p=0.85$ & $p=0.84$ & $p=0.0001^{*}$ \\
\hline $\begin{array}{l}\text { Tumor emboli in } \\
\text { CD34-positive } \\
\text { vessels }\end{array}$ & $p=0.11$ & $p=0.37$ & $p=0.0004^{*}$ & $p=0.00003^{*}$ & $p=0.0003^{*}$ & $p=0.89$ & $p=0.94$ & $p=0.09$ \\
\hline $\begin{array}{l}\text { Tumor emboli in } \\
\text { podoplanin- } \\
\text { positive vessels }\end{array}$ & $p=0.25$ & $p=0.75$ & $p=0.005^{*}$ & $p=0.004^{*}$ & $p=0.26$ & $p=0.21$ & $p=0.17$ & $p=0.0001^{*}$ \\
\hline Recurrence & $p=0.42$ & $p=0.09$ & $p=0.0005^{*}$ & $p=0.0001^{*}$ & $p=0.007^{*}$ & $p=0.51$ & $p=0.09$ & $p=0.28$ \\
\hline
\end{tabular}

the lymphoid and polymorphic cell infiltrates of tumor stroma. The mechanism of their formation and the role in tumor progression are not quite understood and require further studies.

\section{Conclusions}

Thus, the results of the study indicate that in cervical cancer, tumor vessels are heterogeneous and differ in morphology 
and clinical significance. The most significant factors from the point of view of early cervical cancer prognosis were DCs with a weak expression of CD34, "contact type DCs," capillaries in the tumor solid component, and lymphatic vessels in the lymphoid and polymorphic cell infiltrates of tumor stroma. However, this study has a number of limitations related to the fact that only patients with early cervical cancer, who had a low risk of disease recurrence, were included in the study. We believe that further studies are needed to verify the assumptions made about the role of different types of tumor vessels in the progression of squamous cervical cancer as well as other types of squamous cell carcinoma.

\section{Data Availability}

The data that support the findings of this study are available from the corresponding author on reasonable request.

\section{Conflicts of Interest}

The authors declare that there are no conflicts of interest regarding the publication of this paper.

\section{Acknowledgments}

This research was funded by the Russian Foundation for Basic Research and the government of the region, grant nos 18-415-560005 and 19-415-560004.

\section{References}

[1] L. A. Torre, F. Bray, R. L. Siegel, J. Ferlay, J. Lortet-Tieulent, and A. Jemal, "Global cancer statistics, 2012," CA: A Cancer Journal for Clinicians, vol. 65, no. 2, pp. 87-108, 2015.

[2] J. Ferlay, M. Colombet, I. Soerjomataram et al., "Estimating the global cancer incidence and mortality in 2018: GLOBOCAN sources and methods," International Journal of Cancer, vol. 144, no. 8, pp. 1941-1953, 2019.

[3] M. Arbyn, E. Weiderpass, L. Bruni et al., "Estimates of incidence and mortality of cervical cancer in 2018: a worldwide analysis," The Lancet Global Health, vol. 8, no. 2, pp. 191-203, 2020.

[4] S. Kubota, E. Kobayashi, M. Kakuda et al., "Retrospective analysis for predictors of parametrial involvement in IB cervical cancer," Journal of Obstetrics and Gynaecology Research, vol. 45, no. 3, pp. 679-685, 2019.

[5] L. M. Bean, K. K. Ward, S. C. Plaxe, and M. T. McHale, "Survival of women with microinvasive adenocarcinoma of the cervix is not improved by radical surgery," American Journal of Obstetrics and Gynecology, vol. 217, no. 3, pp. 332.e1-332.e6, 2017.

[6] J. Y. Yoneda, J. F. Braganca, L. O. Sarian, P. P. Borba, J. C. J. Conceição, and L. C. Zeferino, "Surgical treatment of microinvasive cervical cancer: analysis of pathologic features with implications on radicality," International Journal of Gynecologic Cancer, vol. 25, no. 4, pp. 694-698, 2015.

[7] K. Matsuo, M. Shimada, T. Saito et al., "Risk stratification models for para-aortic lymph node metastasis and recurrence in stage IB-IIB cervical cancer," Journal of Gynecologic Oncology, vol. 29, no. 1, p. 11, 2018.
[8] K. Matsuo, M. Shimada, Y. Aoki et al., "Comparison of adjuvant therapy for node-positive clinical stage IB-IIB cervical cancer: systemic chemotherapy versus pelvic irradiation," International Journal of Cancer, vol. 141, no. 5, pp. 1042-1051, 2017.

[9] M. Takekuma, Y. Kasamatsu, N. Kado et al., "Adjuvant chemotherapy versus concurrent chemoradiotherapy for high-risk cervical cancer after radical hysterectomy and systematic lymphadenectomy," International Journal of Clinical Oncology, vol. 21, no. 4, pp. 741-747, 2016.

[10] K. Tsuchida, N. Murakami, T. Kato et al., "Postoperative pelvic intensity-modulated radiation therapy reduced the incidence of late gastrointestinal complications for uterine cervical cancer patients," Journal of Radiation Research, vol. 60 , no. 5, pp. 650-657, 2019.

[11] H. Machida, K. Matsuo, A. Furusawa, T. Kita, R. Kitagawa, and M. Mikami, "Profile of treatment-related complications in women with clinical stage IB-IIB cervical cancer: a nationwide cohort study in Japan," PLoS One, vol. 14, no. 1, Article ID e0210125, 2019.

[12] A. Shankar, J. Patil, N. Sethi et al., "Urinary dysfunction assessment in long-term survivors of carcinoma cervix using LENT SOMA scale: an Indian study addressing quality of life issues," Asian Pacific Journal of Cancer Prevention, vol. 20, no. 2, pp. 383-389, 2019.

[13] T. Yamada, S. Ishihara, M. Kawai, Y. Itoh, S. Naganawa, and M. Ikeda, "Analysis of late adverse events and their chronological changes after radiation therapy for cervical cancer," Nagoya Journal of Medical Science, vol. 80, no. 4, pp. 487-496, 2018.

[14] L. M. Randall, B. J. Monk, K. M. Darcy et al., "Markers of angiogenesis in high-risk, early-stage cervical cancer: a gynecologic oncology group study," Gynecologic Oncology, vol. 112, no. 3, pp. 583-589, 2009.

[15] X. Hu, H. Liu, M. Ye, and X. Zhu, "Prognostic value of microvessel density in cervical cancer," Cancer Cell International, vol. 18, no. 1, p. 152, 2018.

[16] J. Zhang, J. Liu, C. Zhu et al., "Prognostic role of vascular endothelial growth factor in cervical cancer: a meta-analysis," Oncotarget, vol. 8, no. 15, pp. 24797-24803, 2017.

[17] B. Muz, P. de la Puente, F. Azab, and A. K. Azab, "The role of hypoxia in cancer progression, angiogenesis, metastasis, and resistance to therapy," Hypoxia, vol. 3, pp. 83-92, 2015.

[18] H. Harada, "Hypoxia-inducible factor 1-mediated characteristic features of cancer cells for tumor radioresistance," Journal of Radiation Research, vol. 57, no. S1, pp. i99-i105, 2016.

[19] L. Zeng, A. Morinibu, M. Kobayashi et al., “Aberrant IDH3 $\alpha$ expression promotes malignant tumor growth by inducing HIF-1-mediated metabolic reprogramming and angiogenesis," Oncogene, vol. 34, no. 36, pp. 4758-4766, 2015.

[20] Y. Goto, L. Zeng, C. J. Yeom et al., "UCHL1 provides diagnostic and antimetastatic strategies due to its deubiquitinating effect on HIF-1 $\alpha$," Nature Communications, vol. 6, no. 1, p. 6153, 2015.

[21] S. Koyama, S. Matsunaga, M. Imanishi et al., “Tumour blood vessel normalisation by prolyl hydroxylase inhibitor repaired sensitivity to chemotherapy in a tumour mouse model," Scientific Reports, vol. 7, no. 1, p. 45621, 2017.

[22] V. B. Orel, M. A. Zabolotny, and V. E. Orel, "Heterogeneity of hypoxia in solid tumours and mechanochemical reactions with oxygen nanobubbles," Medical Hypotheses, vol. 102, pp. 82-86, 2017. 
[23] J.-S. Park, I.-K. Kim, S. Han et al., "Normalization of tumor vessels by Tie2 activation and Ang2 inhibition enhances drug delivery and produces a favorable tumor microenvironment," Cancer Cell, vol. 30, no. 6, pp. 953-967, 2016.

[24] J. A. Jiménez-Torres, M. Virumbrales-Muñoz, K. E. Sung, M. H. Lee, E. J. Abel, and D. J. Beebe, "Patient-specific organotypic blood vessels as an in vitro model for anti-angiogenic drug response testing in renal cell carcinoma," EBioMedicine, vol. 42, pp. 408-419, 2019.

[25] P. Carmeliet and R. K. Jain, "Principles and mechanisms of vessel normalization for cancer and other angiogenic diseases," Nature Reviews Drug Discovery, vol. 10, no. 6, pp. 417-427, 2011.

[26] H. F. Dvorak, "Tumor stroma, tumor blood vessels, and antiangiogenesis therapy," The Cancer Journal, vol. 21, no. 4, pp. 237-243, 2015.

[27] S. Niland and J. A. Eble, "Integrin-Mediated cell-matrix interaction in physiological and pathological blood vessel formation," Journal of Oncology, vol. 2012, Article ID 125278, 25 pages, 2012.

[28] F. Fan, A. Schimming, D. Jaeger, and K. Podar, "Targeting the tumor microenvironment: focus on angiogenesis," Journal of Oncology, vol. 2012, Article ID 281261, 16 pages, 2012.

[29] C.-N. Qian, M.-H. Tan, J.-P. Yang, and Y. Cao, "Revisiting tumor angiogenesis: vessel co-option, vessel remodeling, and cancer cell-derived vasculature formation," Chinese Journal of Cancer, vol. 35, no. 1, p. 10, 2016.

[30] F. Pezzella, K. Gatter, and C.-N. Qian, "Twenty years after: the beautiful hypothesis and the ugly facts," Chinese Journal of Cancer, vol. 35, no. 1, p. 22, 2016.

[31] M. Senchukova and M. V. Kiselevsky, "The "cavitary" type of angiogenesis by gastric cancer. Morphological characteristics and prognostic value," Journal of Cancer, vol. 5, no. 5, pp. 311-319, 2014.

[32] M. A. Senchukova, N. V. Nikitenko, O. N. Tomchuk, N. V. Zaitsev, and A. A. Stadnikov, "Different types of tumor vessels in breast cancer: morphology and clinical value," Springerplus, vol. 4, no. 1, p. 512, 2015.

[33] I. Helfrich, I. Scheffrahn, S. Bartling et al., "Resistance to antiangiogenic therapy is directed by vascular phenotype, vessel stabilization, and maturation in malignant melanoma," The Journal of Experimental Medicine, vol. 207, no. 3, pp. 491-503, 2010.

[34] R. Barnhill, P. J. Dam, P. Vermeulen et al., "Replacement and desmoplastic histopathological growth patterns in cutaneous melanoma liver metastases: frequency, characteristics, and robust prognostic value," The Journal of Pathology: Clinical Research, vol. 6, no. 3, pp. 195-206, 2020.

[35] P. B. Vermeulen, G. Gasparini, S. B. Fox et al., "Second international consensus on the methodology and criteria of evaluation of angiogenesis quantification in solid human tumours," European Journal of Cancer, vol. 38, no. 12, pp. 1564-1579, 2002.

[36] G. Acs, G. Paragh, Z. Rakosy, C. Laronga, and P. J. Zhang, "The extent of retraction clefts correlates with lymphatic vessel density and VEGF-C expression and predicts nodal metastasis and poor prognosis in early-stage breast carcinoma," Modern Pathology, vol. 25, no. 2, pp. 163-177, 2012.

[37] Y. Hou, S. Guo, J. Lyu et al., "Prognostic factors in Asian and white American patients with cervical cancer, considering competing risks," Current Oncology, vol. 26, no. 3, pp. 277$285,2019$.

[38] K. Shimamoto, T. Saito, S. Kitade et al., "A study of treatments and outcomes in elderly women with cervical cancer,"
European Journal of Obstetrics \& Gynecology and Reproductive Biology, vol. 228, pp. 174-179, 2018.

[39] M. Tang, Q. Liu, X. Yang et al., "Perineural invasion as a prognostic risk factor in patients with early cervical cancer," Oncology Letters, vol. 17, pp. 1101-1107, 2019.

[40] C. M. Hong, S. H. Park, G. O. Chong et al., "Enhancing prognosis prediction using pre-treatment nodal SUVmax and HPV status in cervical squamous cell carcinoma," Cancer Imaging, vol. 19, p. 43, 2019.

[41] H. N. Lee, M. K. Mahajan, S. Das, J. Sachdeva, and M. S. Tiwana, "Early hematological effects of chemo-radiation therapy in cancer patients and their pattern of recovery-a prospective single institution study," Gulf Journal of Oncology, vol. 1, pp. 43-51, 2015.

[42] Y. Ma, G. Zhao, J. Qi et al., "Neoadjuvant brachytherapy and chemotherapy followed by radical surgery for stage IB2 and IIA cervical cancer: a retrospective comparison with chemoirradiation," Molecular and Clinical Oncology, vol. 8, pp. 623-627, 2018.

[43] F. Landoni, A. Colombo, R. Milani, F. Placa, V. Zanagnolo, and C. Mangioni, "Randomized study between radical surgery and radiotherapy for the treatment of stage IB-IIA cervical cancer: 20-year update," Journal of Gynecologic Oncology, vol. 28, no. 3, p. 34, 2017.

[44] Y. M. Liu, L. Q. Ni, S. S. Wang, Q. L. Lv, W. J. Chen, and S. P. Ying, "Outcome and prognostic factors in cervical cancer patients treated with surgery and concurrent chemoradiotherapy: a retrospective study," World Journal of Surgical Oncology, vol. 16, no. 1, p. 18, 2018.

[45] L. B. Rivera and G. Bergers, "Tumor angiogenesis, from foe to friend,” Science, vol. 349, no. 6249, pp. 694-695, 2015.

[46] A. Yehya, M. Asif, S. Petersen et al., "Angiogenesis: managing the culprits behind tumorigenesis and metastasis," Medicina, vol. 54, no. 1, p. 8, 2018.

[47] M. R. Kraby, S. Opdahl, L. A. Akslen, and A. M. Bofin, "Quantifying tumour vascularity in non-luminal breast cancers," Journal of Clinical Pathology, vol. 70, no. 9, pp. 766-774, 2017.

[48] L. M. Luo, H. Xia, R. Shi, J. Zeng, X. R. Liu, and M. Wei, “The association between aquaporin-1 expression, microvessel density and the clinicopathological features of hepatocellular carcinoma," Oncology Letters, vol. 14, pp. 7077-7084, 2017.

[49] E. A. Kuczynski, P. B. Vermeulen, F. Pezzella, R. S. Kerbel, and A. R. Reynolds, "Vessel co-option in cancer," Nature Reviews Clinical Oncology, vol. 16, no. 8, pp. 469-493, 2019.

[50] H. Li, N. Huang, W. Zhu et al., "Modulation the crosstalk between tumor-associated macrophages and non-small cell lung cancer to inhibit tumor migration and invasion by ginsenoside Rh2,” BMC Cancer, vol. 18, no. 1, p. 579, 2018.

[51] S. Osinsky, L. Bubnovskaya, I. Ganusevich et al., "Hypoxia, tumour-associated macrophages, microvessel density, VEGF and matrix metalloproteinases in human gastric cancer: interaction and impact on survival," Clinical and Translational Oncology, vol. 13, no. 2, pp. 133-138, 2011.

[52] Y. L. Wen and L. Li, "Correlation between matrix metalloproteinase-9 and vascular endothelial growth factor expression in lung adenocarcinoma," Genetics and Molecular Research, vol. 14, no. 4, pp. 19342-19348, 2015.

[53] B. Zheng, D. Hao, H. Guo, and B. He, "Correlation between the progression of cancer and the expression of matrix metalloproteinase-9 in metastatic spinal tumor," JBUON, vol. 23, pp. 1534-1539, 2018.

[54] N. S. Kim, Y.-J. Kang, J.-O. Jo et al., "Elevated expression of thymosin $\beta 4$, vascular endothelial growth factor (VEGF), and 
hypoxia inducible factor (HIF)- $1 \alpha$ in early-stage cervical cancers," Pathology \& Oncology Research, vol. 17, no. 3, pp. 493-502, 2011.

[55] H. Sun, F. Tang, S. Zhou et al., "Association between vascular endothelial growth factor expression and lymph node metastasis in cervical cancer: a meta-analysis," Journal of $\mathrm{Ob}$ stetrics and Gynaecology Research, vol. 42, no. 10, pp. 1310-1316, 2016.

[56] A. Yanni, Y. Li, and S. Zhao, "The expression and underlying angiogenesis effect of DPC4 and VEGF on the progression of cervical carcinoma," Oncology Letters, vol. 15, pp. 2534-2540, 2018.

[57] B. Sitohy, S. Chang, T. E. Sciuto et al., "Early actions of antivascular endothelial growth factor/vascular endothelial growth factor receptor drugs on angiogenic blood vessels," The American Journal of Pathology, vol. 187, no. 10, pp. 2337-2347, 2017.

[58] A. Birau, R. A. Ceausu, A. M. Cimpean, P. Gaje, M. Raica, and T. Olariu, "Assessement of angiogenesis reveals blood vessel heterogeneity in lung carcinoma," Oncology Letters, vol. 4, no. 6, pp. 1183-1186, 2012.

[59] R. L. Eefsen, G. G. Van den Eynden, G. Høyer-Hansen et al., "Histopathological growth pattern, proteolysis and angiogenesis in chemonaive patients resected for multiple colorectal liver metastases," Journal of Oncology, vol. 2012, Article ID 907971, 12 pages, 2012.

[60] P. R. Castro, A. S. Barbosa, J. M. Pereira et al., "Cellular and molecular heterogeneity associated with vessel formation processes," BioMed Research International, vol. 2018, Article ID 6740408, 32 pages, 2018.

[61] R. Paduch, "The role of lymphangiogenesis and angiogenesis in tumor metastasis," Cellular Oncology, vol. 39, no. 5, pp. 397-410, 2016.

[62] I. Zuazo-Gaztelu and O. Casanovas, "Unraveling the role of angiogenesis in cancer ecosystems," Frontiers in Oncology, vol. 8, p. 248, 2018.

[63] T. Kucera, B. Strilić, K. Regener, M. Schubert, V. Laudet, and E. Lammert, "Ancestral vascular lumen formation via basal cell surfaces," PLoS One, vol. 4, Article ID e4132, 2009.

[64] A. Valdivia, G. Mingo, V. Aldana et al., "Fact or fiction, it is time for a verdict on vasculogenic mimicry?" Frontiers in Oncology, vol. 9, p. 680, 2019.

[65] B. Sun, D. Zhang, N. Zhao, and X. Zhao, "Epithelial-to-endothelial transition and cancer stem cells: two cornerstones of vasculogenic mimicry in malignant tumors," Oncotarget, vol. 8, no. 18, pp. 30502-30510, 2017.

[66] M. L. Iruela-Arispe and G. J. Beitel, "Tubulogenesis," Development, vol. 140, no. 14, pp. 2851-2855, 2013.

[67] C. Viswanathan, R. Kulkarni, A. Bopardikar, and S. Ramdasi, "Significance of CD34 negative hematopoietic stem cells and CD34 positive mesenchymal stem cells - a valuable dimension to the current understanding," Kopp. Stem. Cell. Res. Ther.vol. 12, pp. 476-483, 2017.

[68] J. C. Sun, F. He, W. Yi et al., "High expression of HIF-2 $\alpha$ and its anti-radiotherapy effect in lung cancer stem cells," Genetics and Molecular Research, vol. 14, no. 4, pp. 18110-18120, 2015.

[69] M. I. Koukourakis, C. Kakouratos, D. Kalamida et al., "Hypoxia-inducible proteins HIF1 $\alpha$ and lactate dehydrogenase LDH5, key markers of anaerobic metabolism, relate with stem cell markers and poor post-radiotherapy outcome in bladder cancer," International Journal of Radiation Biology, vol. 92, no. 7, pp. 353-363, 2016.

[70] B. Zhang, W. Niu, H. Y. Dong, M. L. Liu, Y. Luo, and Z. C. Li, "Hypoxia induces endothelial-mesenchymal transition in pulmonary vascular remodeling," International Journal of Molecular Medicine, vol. 42, pp. 270-278, 2018. 